\title{
Avaliação do desempenho estrutural de treliças Howe de Bambu Laminado Colado
}

\author{
Evaluation of the structural performance Howe trusses \\ made of Glued Laminated Bamboo
}

Douglas Mateus de Lima Universidade Federal de Pernambuco Caruaru - PE - Brasil

Mariana Mendes Amorin Universidade Federal de Pernambuco Caruaru - PE - Brasil

Humberto Correia Lima Júnior Universidade Federal de Pernambuco Caruaru - PE - Brasil

Normando Perazzo Barbosa Universidade Federal da Paraíba João Pessoa - PB - Brasil

Fábio Luiz Wilrich ITAIPU Binacional Foz do Iguaçu - PR - Brasil

Recebido em 12/05/13 Aceito em 19/05/15

\section{Douglas Mateus de Lima \\ Mariana Mendes Amorim \\ Humberto Correia Lima Júnior \\ Normando Perazzo Barbosa \\ Fábio Luiz Wilrich}

\section{Resumo}

$\mathbf{N}$

este trabalho, apresenta-se e discute-se o comportamento estrutural de modelos reduzidos de treliças tipo Howe fabricadas com Bambu Laminado Colado (BLC). Foi utilizado o bambu da espécie

Dendrocalamus giganteus Munro para a confecção das treliças, que foram preparadas com dois tipos de adesivos: um à base de resorcinol-formaldeído e outro à base de poliacetato de vinila. As treliças apresentavam vão livre de $2,5 \mathrm{~m}$ e altura de $0,4 \mathrm{~m}$. Para o projeto das treliças, fez-se uma análise prévia de suas ligações que apresentavam três variáveis de estudo: o ângulo de montagem das ligações, o tipo de adesivo empregado e o número de ripas de bambu utilizadas para confecção dos espécimes. Todas as treliças romperam por flambagem nas diagonais comprimidas, suportando uma carga, em média, 175\% superior àquela prevista no projeto. Finalmente, verificou-se que as ligações e as treliças de BLC apresentaram desempenho estrutural adequado.

Palavras-chaves: Bambu. Adesivo. Treliça Howe.

\section{Abstract}

This paper presents and discusses the experimental analyses of reduced models of Howe trusses made from Glued Laminated Bamboo (GLB). Dendrocalamus giganteus bamboo was used to make the trusses' battens, which had their bamboo layer glued with two types of glue (resorcinol-formaldehyde and polyvinyl acetate). The trusses were $2.5 \mathrm{~m}$ long and $0.4 \mathrm{~m}$ high. In order to design the trusses, a prior analysis of their joints was made, and three variables were investigated: the angle of the joints, the number of batten layers and the glue types. All trusses failed by buckling with a load $175 \%$ higher than the design load. Finally, it was observed that the joints and the GLB trusses presented suitable structural behavior.

Keywords: Bamboo. Glue. Howe Truss. 


\section{Introdução}

Um dos parâmetros utilizados para avaliação do índice de desenvolvimento humano (IDH) são as condições de habitação das moradias de determinada população. Pode-se afirmar que a falta de qualidade e de moradias dignas nas áreas rurais dos países em desenvolvimento é um problema presente. No Brasil, particularmente na região Nordeste, a maioria das construções de baixa renda é feita com varas de vegetação local recobertas com argila, sem o mínimo emprego de tecnologia. De uma forma geral, tais construções apresentam péssima aparência estética, baixa resistência às intempéries e grande número de fissuras, o que propicia o alojamento de insetos transmissores de doenças, tais como o mal de Chagas.

A baixa qualidade das construções supracitadas se deve, entre outros fatores, ao fato de que a aquisição de materiais industrializados necessita de recursos significativos, o que torna proibitivo seu uso em habitações destinadas às populações com baixa renda. Em adição, verifica-se grande resistência por parte dos profissionais da engenharia na utilização de materiais não convencionais, aversão que é causada principalmente pela falta de conhecimento sólido sobre as propriedades físicas e mecânicas desses materiais e da ausência de códigos normativos que forneçam embasamento técnico para a tomada de decisões e o desenvolvimento de projetos.

Além disso, o crescimento da população mundial tem implicado o consumo excessivo e desordenado dos recursos naturais. Muitos desses recursos naturais, tais como a madeira, têm sua produção próxima do colapso. Observa-se que as reservas de florestas tropicais representam cerca de 900 milhões de hectares; já o desmatamento ocorre à taxa de 16 milhões de hectares por ano (ROSA, 2002). Dentro dessa perspectiva, constata-se que em cerca de meio século essas florestas serão extintas.

Nesse contexto, observa-se que o bambu, de modo particular o bambu laminado colado (BLC), é um material de construção que pode vir a colaborar na melhoria das condições das moradias. Além disso, esse vegetal poderia colaborar na sustentabilidade do planeta, uma vez que sua produção é rápida e necessita de baixo consumo energético. $\mathrm{O}$ bambu é um material cujas propriedades mecânicas adequadas indicam grande potencial a ser explorado pela engenharia. A planta apresenta longos colmos, geralmente ocos, os quais são fechados a intervalos relativamente regulares por um diafragma nas regiões dos nós; suas paredes têm excelente resistência à tração e à compressão, comparáveis às mais nobres madeiras, ressaltandose ainda seu baixo peso específico, da ordem de $7,7 \mathrm{kN} / \mathrm{m}^{3}$ (LIMA, 2013). Apesar de suas formidáveis propriedades físico-mecânicas, existem dois fatores básicos, de cunho técnico, que reduzem a utilização do bambu na indústria da construção civil brasileira: sua configuração geométrica, que impossibilita a confecção de peças estruturais usuais, como vigas e pilares de seções transversais retangulares; e sua baixa resistência ao cisalhamento, que não permite a cravação de pinos, o que torna difícil o projeto de estruturas de maior porte, em que se necessitam de emendas ou ligações (MESQUITA et al., 2006). No entanto, a tecnologia do BLC basicamente elimina os problemas de cisalhamento $\mathrm{e}$ da geometria particular dos colmos, permitindo, dessa forma, que esse material tenha uma utilização mais racional na engenharia estrutural (LIMA JUNIOR.; DIAS, 2001)

Enfatiza-se que para a produção do BLC é necessário que os colmos apresentem características geométricas que possibilitem a extração das ripas, ou seja, são necessários colmos com retidão considerável e com espessas paredes. Essas características são mais comuns em espécies pertencentes aos gêneros Dendrocalamus, Guadua e Phyllostachys. Como o colmo apresenta variação de geometria ao longo da altura, com redução do diâmetro e da espessura de sua parede (GHAVAMI; RODRIGUES; PACIORNIK, 2003), as regiões mais aproveitadas para a produção do BLC são a basal e a intermediária. Dessa forma, para que o BLC seja mais popularizado como material de construção, são necessários estudos tecnológicos e agronômicos para implantação de processos de beneficiamento do bambu que apresentem elevada taxa de aproveitamento do colmo, resultando na diminuição do custo de fabricação. Como exemplos citam-se os processos de fabricação empregados em países como a China e a Colômbia, que têm larga experiência na utilização do bambu em suas diversas formas (papel, alimento, móveis, pisos, construção civil, artesanato, embarcações, encanamentos e outros); entre elas se destacam aqui as construções de residências populares e de grandes obras (pontes, passarelas, telhados, templos religiosos, etc.) que utilizam o colmo in natura.

A ideia de utilização do BLC para fins de elementos estruturais no Brasil é recente e ainda necessita que sejam desenvolvidas pesquisas mais aprofundadas. Inicialmente, observa-se a necessidade de desenvolvimento de equipamentos adequados para a laminação do bambu de modo

86 Lima, D. M. de; Amorim, M. M.; Lima Júnior, H. C.; Barbosa, N. P.; Wilrich, F. L. 
industrial. O tipo de adesivo é outro ponto que precisa ser investigado, uma vez que é fundamental que apresente baixo custo e alta resistência e que interaja quimicamente de modo efetivo com o bambu. O processo de colagem das tiras de bambu deve ser otimizado com o objetivo de reduzir o custo de beneficiamento do BLC. Adicionalmente, verifica-se a necessidade de desenvolvimento de um tratamento adequado contra o ataque de fungos e insetos, de modo a garantir durabilidade ao material, sem que tal tratamento interfira negativamente no adesivo. Finalmente, deve ser buscada a determinação do comportamento desse material quando empregado como elemento estrutural.

Com base nesse contexto, este trabalho visou estudar o comportamento do BLC compondo modelos reduzidos de treliças do tipo Howe por meio de ensaios experimentais. Inicialmente, realizou-se um estudo das ligações das barras de BLC; em seguida, quatro treliças foram ensaiadas. Investigou-se o comportamento de dois tipos de adesivos:

(a) um à base de resorcinol-formaldeído (RF); e

(b) outro à base de poliacetato de vinila (PVA).

\section{Materiais e métodos}

\section{Método de dimensionamento das treliças}

As treliças planas geralmente servem de sustentação para telhados e pontes; assim, as treliças utilizadas em coberta de edificações têm a função estrutural de receber e transmitir a carga do telhado para os pontos de apoio de maneira eficiente e econômica.

Considera-se que as cargas atuam sobre nós superiores da estrutura; assim, utiliza-se o critério da faixa de influência para se obter a carga atuante sobre cada nó. A faixa de influência é adotada tomando-se a soma das duas metades das distâncias entre os dois nós adjacentes. Dessa forma, atuam em cada um desses nós as cargas que agem na região de influência: madeira, telhas, vento, contraventamentos, ferragens, peças especiais e sobrecargas. Moliterno (2010) estabelece os seguintes pesos distribuídos dos elementos constituintes de uma cobertura: forro do tipo Eucatex com valor igual a $0,035 \mathrm{kN} / \mathrm{m}^{2}$ mais estrutura de sustentação com madeira do tipo conífera com valor máximo igual a $0,120 \mathrm{kN} / \mathrm{m}^{2}$, que compõem a carga proveniente do forro $\left(g_{F}\right)$; telhas de PVC rígido com perfil cimento-amianto $\left(g_{i}\right)$ de valor $0,020 \mathrm{kN} / \mathrm{m}^{2}$, as quais devem ser postas em projeção horizontal $\left(g_{c}\right)$ para poder-se somar às demais cargas e multiplicar-se a área de influência medida também em projeção horizontal; terças para chapas onduladas de cimento amianto $\left(g_{0}\right)$ com o valor de $0,045 \mathrm{kN} / \mathrm{m}^{2}$, para um vão máximo de $4,00 \mathrm{~m}$; e peso próprio da tesoura e do contraventamento $\left(g_{T}\right)$ pela fórmula empírica de Howe, conforme a Equação 1:

$g_{T}=0,0245(1+0,33 L)$

Eq. 1

Onde:

$g_{T}$ é o peso próprio da tesoura, inclusive contraventamento, em kN/m²; e

$L$ é o vão teórico da tesoura, em metros.

Portanto, a carga permanente é dada pela Equação 2:

$g=g_{c}+g_{0}+g_{T}+g_{F}+g_{m}$

Eq. 2

Onde:

$g$ é a carga permanente total;

$g_{c}$ é a carga permanente das telhas;

$g_{0}$ é a carga permanente das terças;

$g_{T}$ é a carga permanente da tesoura;

$g_{F}$ é a carga permanente do forro e da estrutura de sustentação; e

$g_{m}$ é a carga permanente das peças metálicas de ligação, estimada como $3 \%$ do peso próprio da madeira da estrutura.

Todas essas cargas permanentes são distribuídas pela área (metros quadrados) em projeção horizontal. As forças devidas ao vento são calculadas de acordo com a norma específica, NBR 6123 (ABNT, 1988).

A segurança de uma estrutura em relação aos estados-limites últimos é obtida, além de condições construtivas a serem atendidas, basicamente pela obediência à Equação 3:

$S_{d} \leq R_{d}$

Eq. 3

Onde:

$S_{d}$ representa a tensão de solicitação de projeto resultante das cargas atuantes na treliça por meio da combinação de ações; e

$R_{d}$ é a resistência de cálculo do BLC.

A verificação da segurança, no que diz respeito aos estados-limites de utilização, é atendida pela observância à Equação 4:

$S_{d, u t i} \leq S_{\text {lim }}$

Eq. 4 
Onde:

$S_{d, u t i}$ são valores decorrentes da aplicação das ações, calculados com a hipótese de comportamento elástico linear da estrutura; e

$S_{\text {lim }}$ é o valor preestabelecido para efeito estrutural que limita o aparecimento do estado-limite considerado.

\section{Materiais}

\section{Bambu}

O bambu utilizado neste estudo foi da espécie Dendrocalamus giganteus Munro, obtido no Zoológico Municipal de Cascavel, PR. Os colmos de bambu, com idade entre 4 e 5 anos, apresentavam comprimento médio de $20 \mathrm{~m}$ e comprimento internodal de $40 \mathrm{~cm}$ a $50 \mathrm{~cm}$. Foram cortados (extraindo-se trechos das regiões basal e intermediária) e deixados secar à sombra, em temperatura ambiente, durante 3 meses; posteriormente, foram secos em estufa a $105^{\circ} \mathrm{C}$, até atingir umidade, em base seca, entre $6 \%$ e $8 \%$. Para os ensaios realizados utilizou-se bambu, aleatoriamente, das regiões basal ou intermediária. Após a secagem e divisão diametral com o auxílio de uma serra circular, os colmos apresentavam comprimento longitudinal de $150 \mathrm{~cm}$. Em seguida, foram extraídas ripas de bambu com dimensões nominais de $150 \mathrm{~cm}$ de comprimento, $0,73 \mathrm{~cm} \mathrm{de}$ espessura e 3,00 cm de largura (Figura 1a e b). As ripas foram aplainadas em uma desengrossadeira e lixadas com uma lixadeira elétrica de três estágios para a regularização das superfícies e padronização da espessura das ripas, em 7,3 mm (Figura 1c). No beneficiamento do colmo, para a fabricação das ripas, eliminaram-se os diafragmas e uma fina camada externa da parede do colmo, pois tais regiões dos colmos apresentavam superfícies muito lisas, que comprometeriam a penetração e a aderência dos adesivos (PEREIRA; BERALDO, 2008).

\section{Adesivos}

Os laminados colados de bambu foram fabricados com dois adesivos: um à base de resina fenólica resorcinol (RF), comercialmente conhecido por Cascophen RS-216-M, composto de um misturador endurecedor FM-60-M; e outro à base de poliacetato de vinila (PVA), com a denominação comercial de Cascorez. Esses adesivos são indicados para prensagem a frio de madeiras (FOREST..., 1999).

O adesivo Cascophen foi escolhido devido a sua eficaz resistência ao cisalhamento e à tração, a partir do ensaio de peças ligadas por colagem; além disso, como esse adesivo é à prova d'água, estruturas coladas sujeitas a umidade devem ter adesivos desse tipo. O adesivo Cascorez, assim como o Cascophen, é bastante utilizado para colagem de peças de madeira, estruturais e não estruturais. Salienta-se que o adesivo Cascorez, em relação ao Cascophen, apresenta menor custo, de 15 a 20 vezes mais barato; menor toxidade, pois é isento do composto químico formaldeído; e menor resistência mecânica ao laminado. Para o preparo dos adesivos seguiram-se as orientações do fabricante.

\section{Material das ligações metálicas (treliças)}

Para a execução das ligações das treliças, foi utilizada chapa de aço 1020 SAE com 1,25 mm de espessura. Para união e transmissão dos esforços nas barras da treliça, foram utilizados parafusos de alta resistência ISO 4016 Classe 8.8, com diâmetro nominal de 5,0 mm, tensão de escoamento igual a $640 \mathrm{MPa}$ e tensão de ruptura igual a $800 \mathrm{MPa}$. Salienta-se que as ligações não seguem inteiramente as recomendações normativas vigentes.

\section{Métodos}

\section{Ligações das treliças planas}

Ensaiaram-se 30 corpos de prova de ligações das treliças para avaliar seus comportamentos e gerar dados para o projeto das treliças. Foi utilizada a distribuição t de Student segundo um intervalo de confiabilidade de $95 \%$ para análise estatística dos dados de resistências das ligações. Os ensaios apresentaram três variáveis, conforme exposto na Tabela 1.

88 Lima, D. M. de; Amorim, M. M.; Lima Júnior, H. C.; Barbosa, N. P.; Wilrich, F. L. 
Figura 1 - Detalhes dos produtos de corte e laminação do bambu

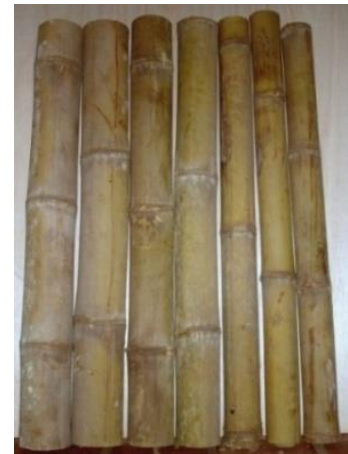

(a) Face externa da parede do colmo

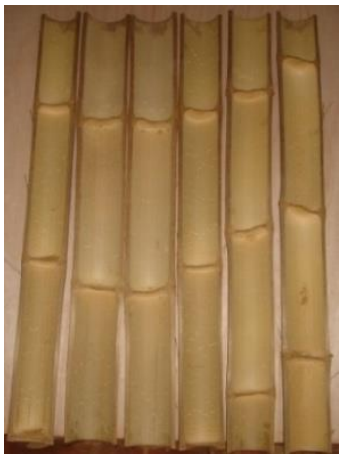

(b) Face interna da parede do colmo

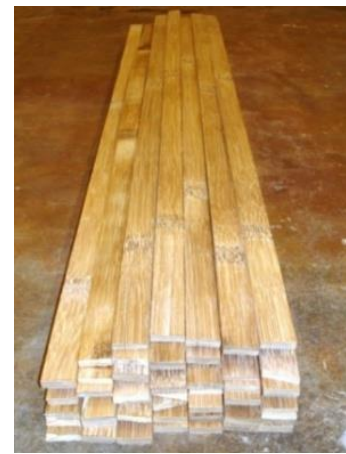

(c) Ripas de bambu após o preparo (utilizadas nesse trabalho)

Tabela 1 - Combinações dos ensaios de ligações das treliças

\begin{tabular}{cccc}
\hline $\begin{array}{c}\text { Ângulo de } \\
\text { montagem }\end{array}$ & Adesivo & $\begin{array}{c}\text { Número } \\
\text { de ripas }\end{array}$ & Combinação \\
\hline \multirow{2}{*}{$0^{\circ}$} & Cascorez & 1 & 0_CASCOREZ_1 \\
\cline { 2 - 4 } & Cascophen & 2 & 0_CASCOREZ_2 \\
\cline { 2 - 4 } & Cascorez & 2 & 0_CASCOPHEN_1 \\
\hline \multirow{2}{*}{$90^{\circ}$} & Cascophen & 1 & 0_CASCOPHEN_2 \\
\cline { 2 - 4 } & & & 90_CASCOREZ_CASCOPHEN_1 \\
\hline
\end{tabular}

Na Figura 2 mostram-se os detalhes dos corpos de prova do ensaio das ligações das treliças, tanto com uma quanto com duas ripas de bambu. Esses ensaios foram realizados em uma máquina universal de ensaios com controle de deslocamento; as cargas foram aplicadas a uma velocidade média de $20 \mathrm{~N} / \mathrm{s}$.

\section{Treliça plana do tipo Howe}

Ensaiaram-se quatro treliças planas do tipo Howe fabricadas com BLC. Duas treliças foram fabricadas utilizando-se adesivo Cascorez, e duas, o adesivo Cascophen. As barras da treliça de seção simples foram fabricadas com BLC elaborado a partir de ripas de bambu, que foram escolhidas aleatoriamente das regiões basal ou intermediária com e sem a presença de nós. Após a limpeza das ripas de bambu com escova de cerdas de nylon, o adesivo foi distribuído entre as ripas com o auxílio de hastes finas e pincel utilizando-se uma gramatura de $215,5 \mathrm{~g} / \mathrm{m}^{2}$. Para colagem, as ripas foram dispostas todas em uma mesma direção paralela às fibras de bambu e foram colocadas no dispositivo de prensagem sob uma pressão de
6,2 $\mathrm{MPa}$, controlada por meio das propriedades dos parafusos de prensagem (número de parafusos, tipo de rosca, passo do parafuso, diâmetro médio, número de voltas aplicada na porca e coeficiente de atrito entre a rosca do parafuso e a porca), conforme mostrado na Figura 3a. O tempo de secagem seguiu as recomendações de cada adesivo utilizado.

Para as barras de seção múltipla, além da fabricação do BLC, realizaram-se a colagem e a prensagem dos espaçadores interpostos, conforme a Figura 3b. Os espaçadores interpostos foram fabricados com madeira mista com as seguintes dimensões: 10,0 cm de comprimento; largura igual a das ripas de bambu; e a espessura igual ao espaçamento entre as ripas de bambu, conforme a Tabela 2. Para o dimensionamento das treliças utilizaram-se as propriedades mecânicas do BLC obtidas por Lima (2013). Na Figura 4 mostra-se o arranjo básico das treliças ensaiadas com detalhes das ligações. Utilizaram-se elementos de madeira mista para compatibilizar as dimensões entre dos banzos (superior e inferior), das diagonais e do montante nos nós de ligação. 
Figura 2 - Corpos de prova das ligações das treliças
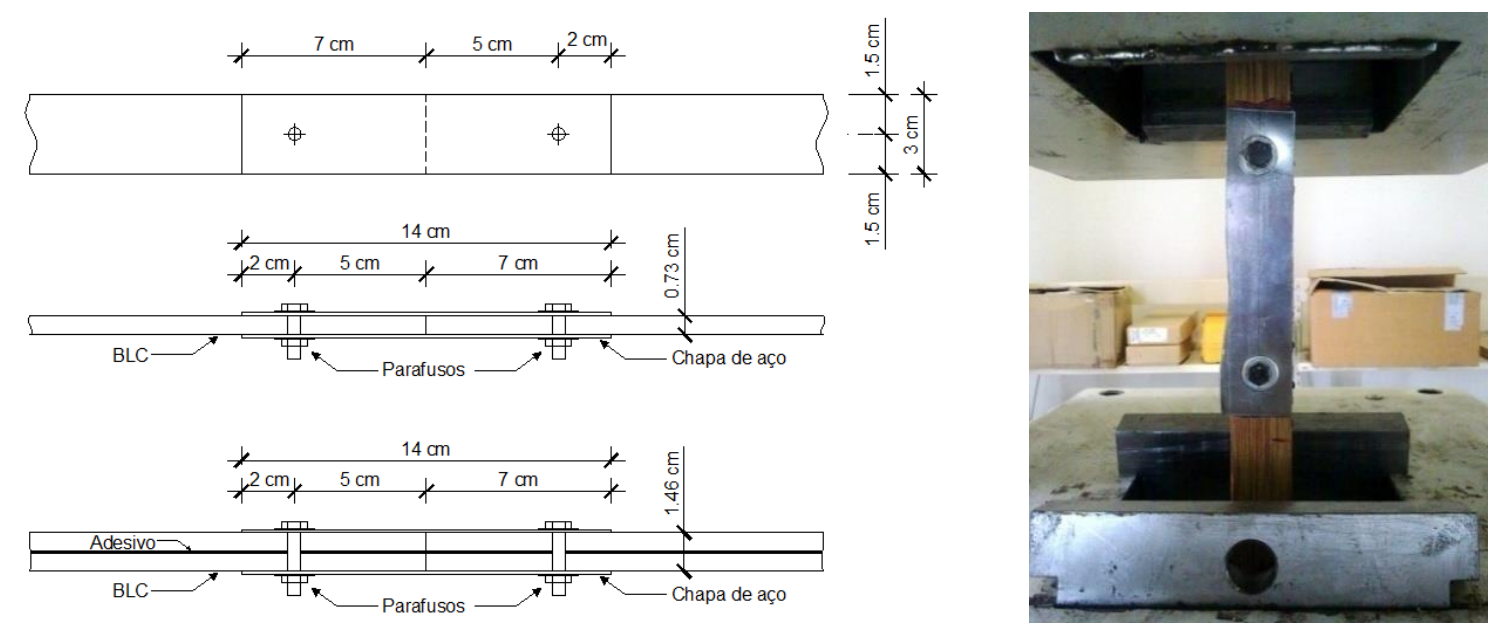

(a) Corpo de prova a $0^{\circ}$ (zero grau) ou paralelo.
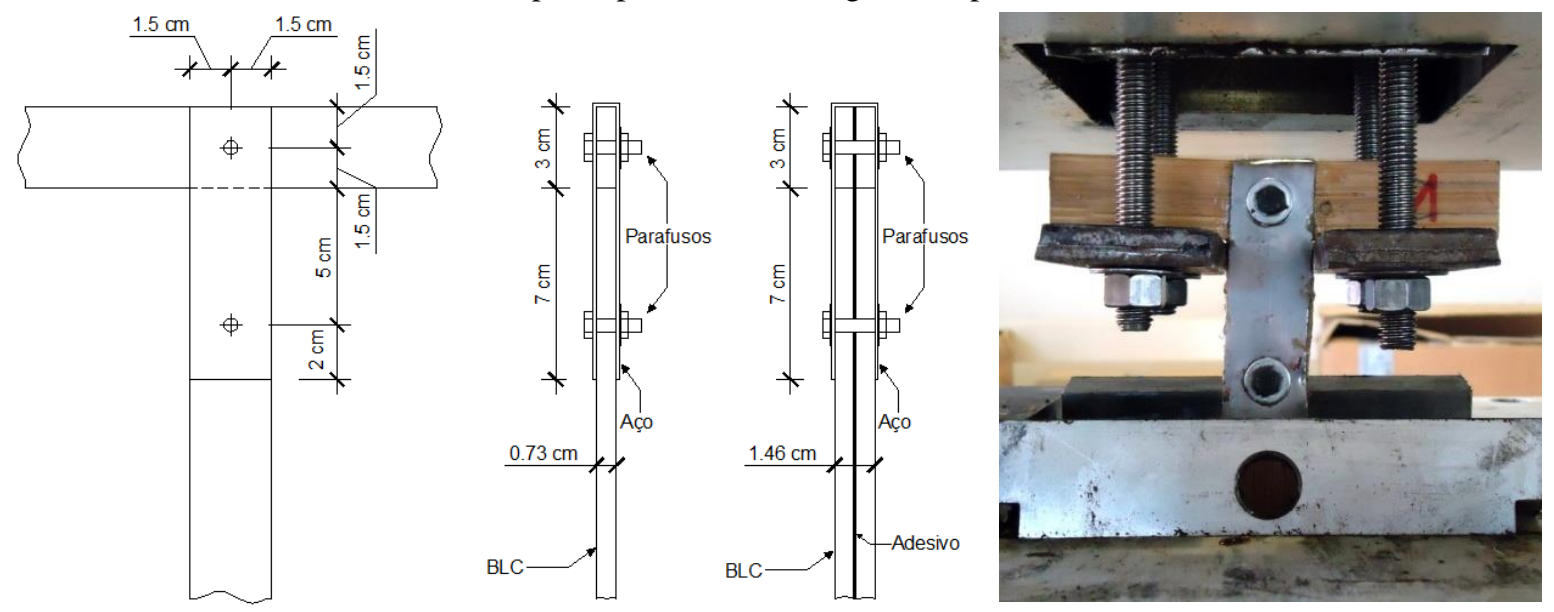

(b) Corpo de prova a $90^{\circ}$ (noventa graus) ou perpendicular.

Figura 3 - Esquema de prensagem das barras da treliça com espaçadores interpostos

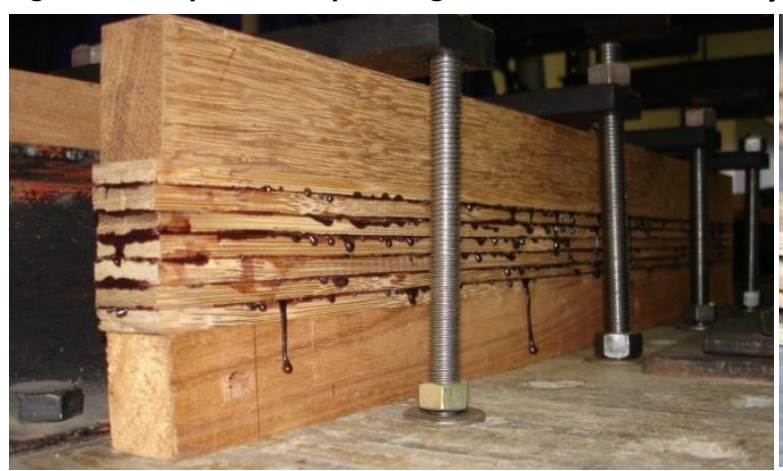

(a) BLC

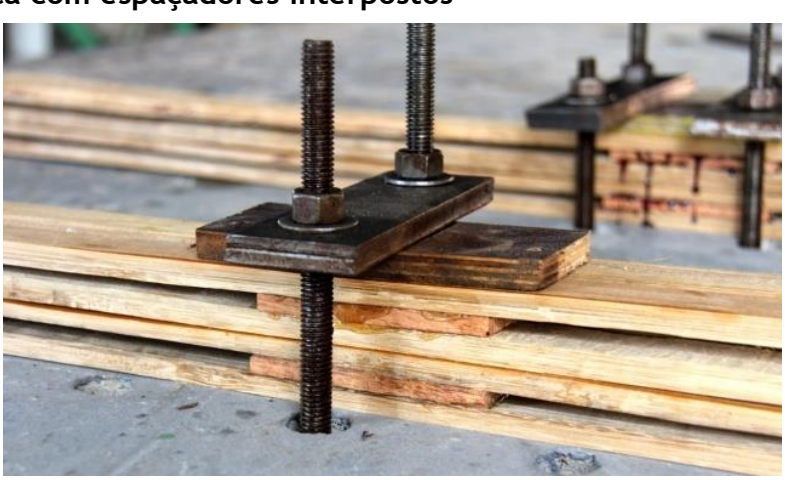

(b) Espaçadores interpostos

90 Lima, D. M. de; Amorim, M. M.; Lima Júnior, H. C.; Barbosa, N. P.; Wilrich, F. L. 
Tabela 2 - Características das barras das treliças planas do tipo Howe

\begin{tabular}{cccccc}
\hline $\begin{array}{c}\mathbf{N}^{\mathbf{0}} \text { da } \\
\text { barra }\end{array}$ & $\begin{array}{c}\text { Quantidade } \\
\text { de ripas }\end{array}$ & Forma de fabricação & $\begin{array}{c}\text { Dimensões da } \\
\text { seção transversal } \\
(\mathbf{m m})\end{array}$ & $\begin{array}{c}\text { Comprimento } \\
\text { s das barras } \\
(\mathbf{c m})\end{array}$ & $\begin{array}{c}\text { Tipo de } \\
\text { seção } \\
\text { transversal }\end{array}$ \\
\hline 1 e 3 & 2 & Colagem das ripas & $14,11 \times 28,93$ & 125,0 & Simples \\
\hline $\begin{array}{c}2,4,8 \\
\text { e } 9\end{array}$ & 3 & $\begin{array}{c}\text { Colagem das ripas } \\
\text { com posterior corte da } \\
\text { peça }\end{array}$ & $\begin{array}{c}2(9,55 \times 28,57) \\
\text { espaçadas de } 8,05\end{array}$ & 65,6 & $\begin{array}{c}\text { Múltipla } \\
\text { (espaçadores } \\
\text { interpostos) }\end{array}$ \\
\hline 5 e 6 & 2 & Ripas isoladas & $\begin{array}{c}2(7,33 \times 29,63) \\
\text { espaçadas de 7,62 }\end{array}$ & 65,6 & $\begin{array}{c}\text { Múltipla } \\
\text { (espaçadores } \\
\text { interpostos) }\end{array}$ \\
\hline 7 & 1 & Ripa isolada & $7,13 \times 29,96$ & 40,0 & Simples \\
\hline
\end{tabular}

Figura 4 - Arranjo básico da treliça do tipo Howe ensaiada

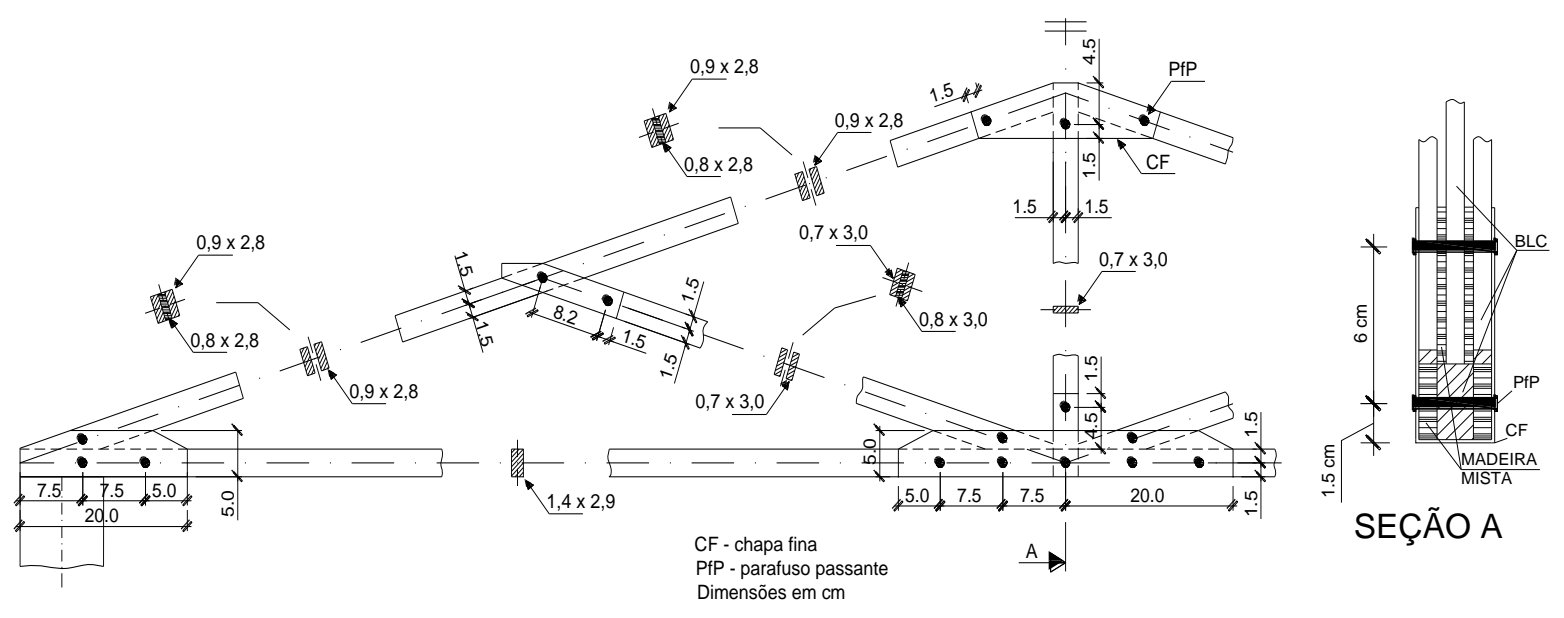

A carga de projeto em cada um dos três nós superiores da treliça foi obtida pela combinação última normal das seguintes cargas distribuídas em projeção horizontal:

(a) peso próprio da treliça Howe $\left(0,045 \mathrm{kN} / \mathrm{m}^{2}\right)$;

(b) peso próprio das terças $\left(0,045 \mathrm{kN} / \mathrm{m}^{2}\right)$; peso próprio do forro tipo Eucatex adicionado de sua estrutura de sustentação $\left(0,155 \mathrm{kN} / \mathrm{m}^{2}\right)$;

(c) vento em sobrepressão, $\left(0,067 \mathrm{kN} / \mathrm{m}^{2}\right)$;

(d) peso próprio das telhas de PVC com perfil cimento-amianto $\left(0,031 \mathrm{kN} / \mathrm{m}^{2}\right)$; e

(e) peso próprio dos elementos metálicos das ligações $\left(0,006 \mathrm{kN} / \mathrm{m}^{2}\right)$.

A carga distribuída de projeto resultante da combinação última normal é igual a $0,465 \mathrm{kN} / \mathrm{m}^{2}$. Considerando a distância entre treliças no telhado igual a 1,8 $\mathrm{m}$ e a distribuição das cargas realizada em três nós, a carga de projeto em cada um dos três nós superiores da treliça resulta igual a $0,70 \mathrm{kN}$, conforme a modelagem das treliças realizada no software Ftool versão 3.00 (Figura 5). Nesta (Figura 5) têm-se os esforços de projeto nos elementos da treliça. Dessa forma, as barras 1 $(3,28 \mathrm{kN}), \quad 3(3,28 \mathrm{kN})$ e $7(0,70 \mathrm{kN})$ foram solicitadas à tração, enquanto as barras 2 $(-3,45 \mathrm{kN}), \quad 4 \quad(-3,45 \mathrm{kN}), \quad 5 \quad(-1,15 \mathrm{kN}), \quad 6$ $(-1,15 \mathrm{kN}), 8(-2,30 \mathrm{kN})$ e $9(-2,30 \mathrm{kN})$ ficaram solicitadas à compressão. Os critérios propostos por Alvim (2009) foram utilizados para as peças comprimidas solidarizadas descontinuamente.

$\mathrm{O}$ ensaio das treliças foi realizado em uma mesa de reação. As cargas foram aplicadas a uma velocidade média de $20 \mathrm{~N} / \mathrm{s}$ por meio de três cilindros hidráulicos conectados cada um a uma célula de carga (C1, C2 e C3 da Figura 6), com capacidade de $100 \mathrm{kN}$. O ensaio foi realizado aplicando-se estágios de carga de intensidade de $0,2 \mathrm{kN}$ em cada ponto.

As treliças foram instrumentadas com quatro extensômetros elétricos (strain gages) dispostos nas barras de maiores esforços (S1, S2, S3 e S4 Figura 6). Utilizaram-se também três medidores de deslocamento potenciométricos LVDT (Linear Variable Differential Transformer) com curso máximo de $100 \mathrm{~mm}$ e sensibilidade de $0,01 \mathrm{~mm}$, postos no banzo inferior da treliça, diretamente 
abaixo dos três pontos de aplicação de carga (L1, L2 e L3 da Figura 6). As leituras das forças, deformações e deslocamentos foram realizadas por um sistema de aquisição de dados, conectado a um computador, com frequência de $2,0 \mathrm{~Hz}$.

Para realização do ensaio das treliças foram empregadas contenções laterais no comprimento médio das barras comprimidas (Figura 7), de forma a reduzir o índice de esbeltez das barras da treliça.

Na Figura 8 mostram-se os dispositivos utilizados no ensaio das treliças.

\section{Resultados e discussão \\ Ligações das treliças planas}

Nos ensaios das ligações a $0^{\circ}$ verificou-se que a ruptura ocorria por cisalhamento na região de embutimento do parafuso sobre o bambu, para todas as combinações de adesivos independentemente do número de ripas utilizadas. Nas Figura 9a e 9b apresentam-se os corpos de prova após o ensaio. Nas Figura 9c e 9d têm-se as características pós-ruptura dos espécimes após a desmontagem dos corpos de prova.

Figura 5 - Modelagem da treliça no software Ftool versão 3.00

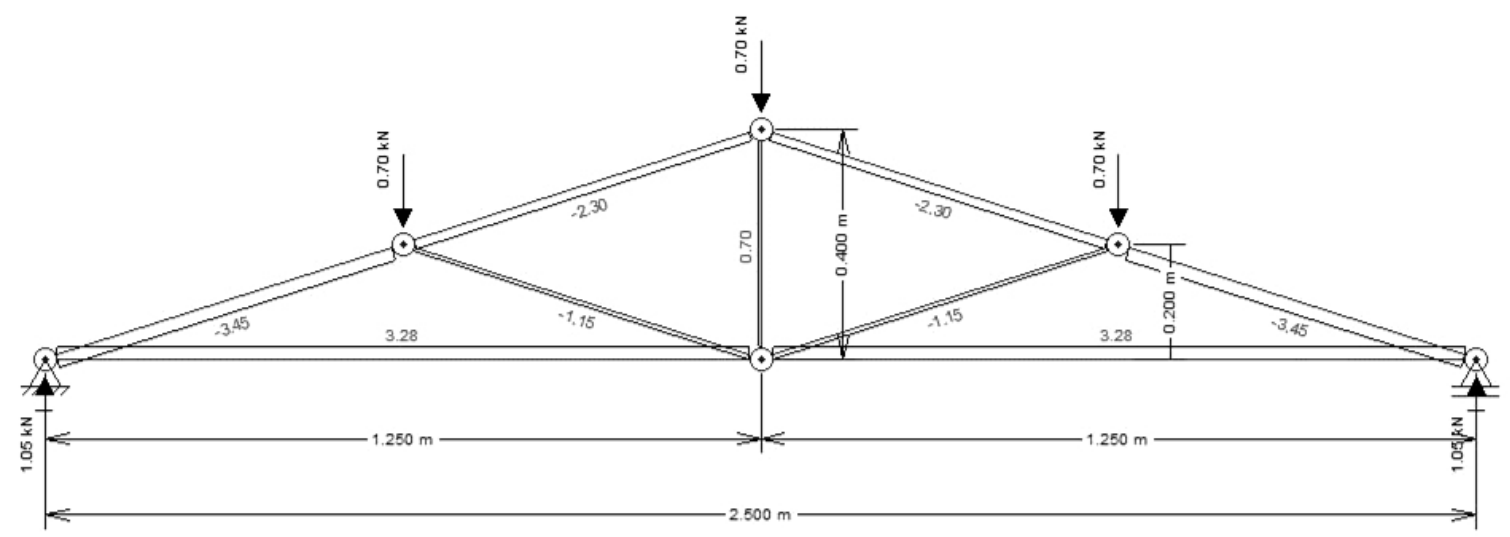

Figura 6 - Esquema reticulado experimental da treliça ensaiada

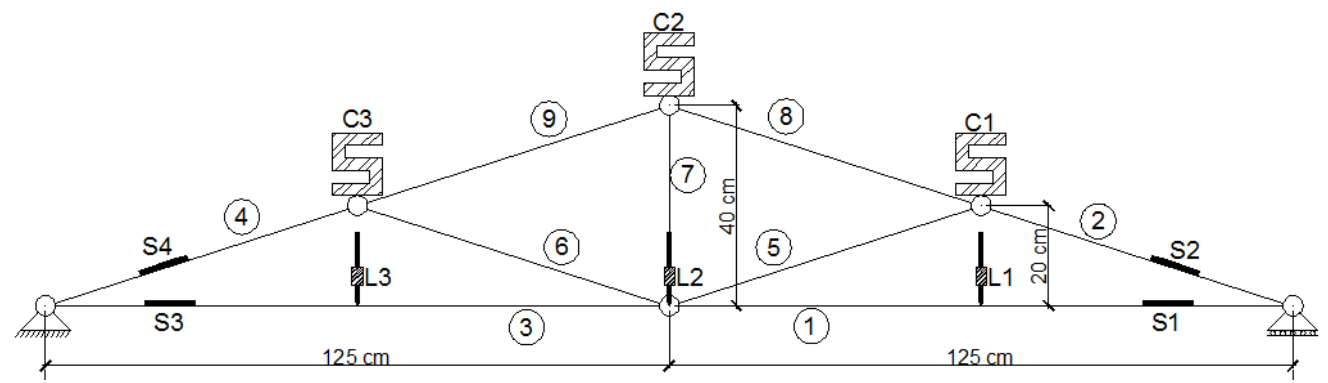

Figura 7 - Detalhe da contenção lateral na treliça ensaiada

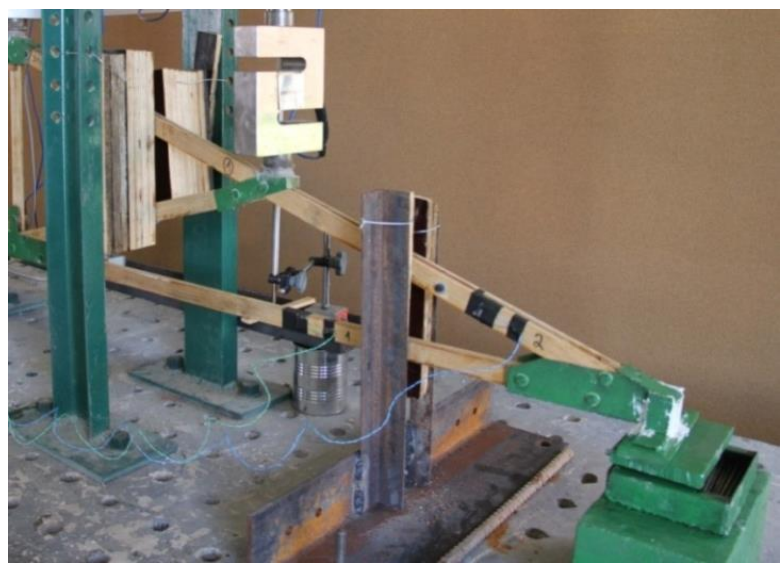

92 Lima, D. M. de; Amorim, M. M.; Lima Júnior, H. C.; Barbosa, N. P.; Wilrich, F. L. 
Figura 8 - Arranjo experimental utilizado no ensaio das treliças planas tipo Howe

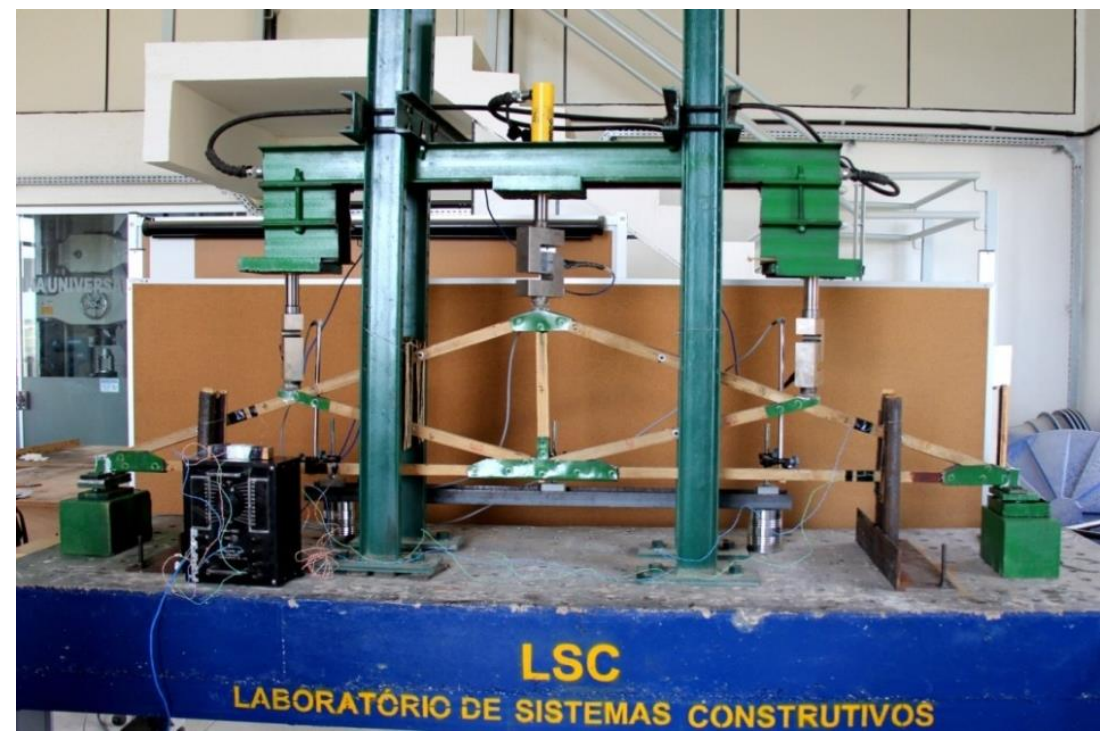

Figura 9 - Detalhes do ensaio das ligações a $0^{\circ}$

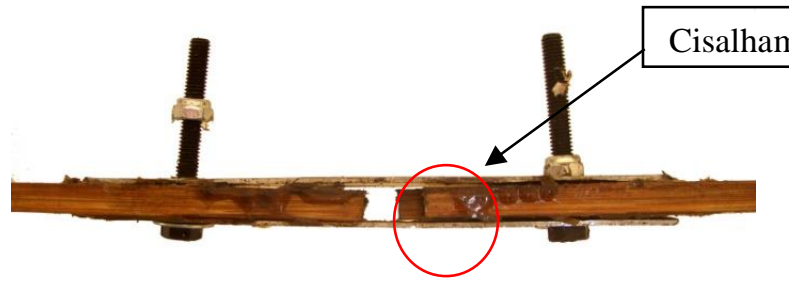

(a) Detalhe de um corpo de prova 0_CASCOREZ_1 após o ensaio

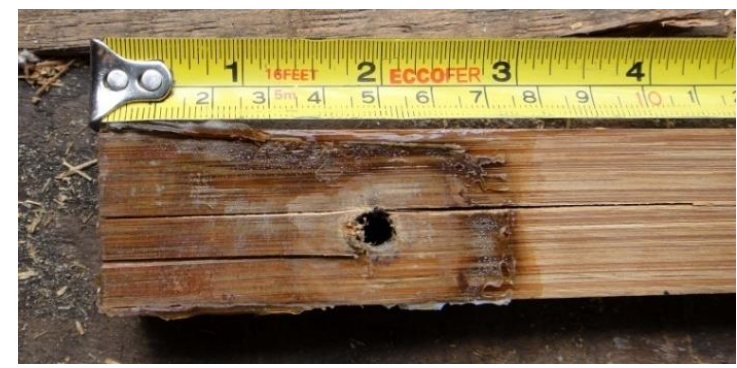

(c) Detalhe de um corpo de prova 0_CASCOREZ_1

A tensão ao cisalhamento na região embutida apresentou os seguintes valores médios:

(a) 7,01 $\mathrm{MPa}(\mathrm{CV}=14,8 \%)$ para o

0_CASCOREZ_1;

(b) 6,37 $\mathrm{MPa}(\mathrm{CV}=8,4 \%)$ para o

0_CASCOPHEN_1;

(c) $5,74 \mathrm{MPa}(\mathrm{CV}=10,3 \%)$ para o

0_CASCOREZ_2;

(d) e 5,25 $\mathrm{MPa}(\mathrm{CV}=10,0 \%)$ para o

0_CASCOPHEN_2.

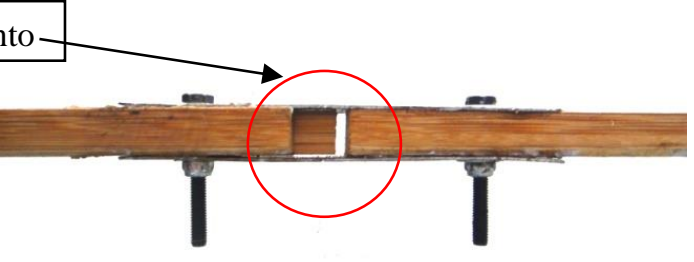

(b) Detalhe de um corpo de prova

0_CASCOREZ_2 após o ensaio

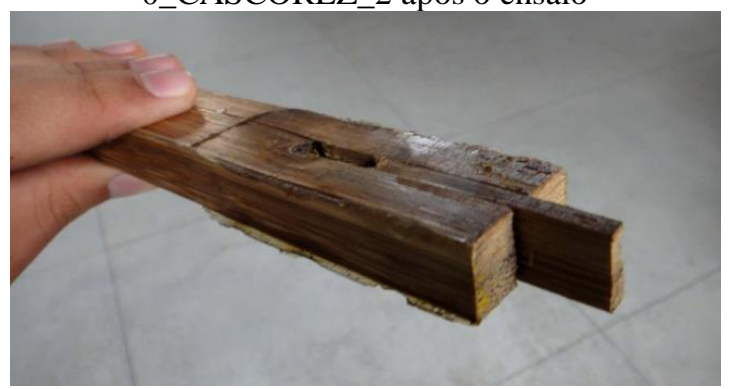

(d) Detalhe de um corpo de prova 0_CASCOREZ_2

Avaliou-se essa tensão de cisalhamento através do teste de hipótese com nível de confiabilidade de 95\% e concluiu-se que o tipo de adesivo utilizado não influencia na tensão ao cisalhamento da região embutida. $\mathrm{Na}$ Figura 10 apresentam-se os resultados da tensão média ao cisalhamento na região de embutimento.

Nos ensaios das ligações a $90^{\circ}$ (paralelo) verificouse que a ruptura ocorria por cisalhamento na região de embutimento do parafuso sobre o bambu ou por tração perpendicular às fibras devido ao fato de a direção de aplicação do esforço ser perpendicular a uma das peças da ligação. Para condições de 
projeto deve-se evitar que as peças estejam submetidas à tração perpendicular às fibras, pois o bambu apresenta baixa resistência a esse tipo de solicitação. Nas Figura 11a e 11b verifica-se o deslocamento devido ao cisalhamento da região embutida. Na Figura 11c observa-se uma fissura devido à baixa resistência à tração perpendicular às fibras do bambu.

A tensão ao cisalhamento na região embutida apresentou os seguintes valores médios: 6,17 MPa $(\mathrm{CV}=6,1 \%)$ para o 90_CASCOREZ_2; e
6,93 $\mathrm{MPa} \quad(\mathrm{CV}=12,6 \%) \quad$ para o

90_CASCOPHEN_1. Na Figura 12 apresentam-se os resultados da tensão média ao cisalhamento na região de embutimento, sendo utilizado um intervalo de confiabilidade de $95 \%$ para a distribuição t de Student. Como foi observado que o tipo de adesivo utilizado não influenciava a resistência das ligações, optou-se por não fabricar e ensaiar as seguintes amostras: 90_CASCOREZ_1 e 90_CASCOPHEN_2.

Figura 10 - Dados da tensão ao cisalhamento na região embutida para ligações a $0^{\circ}$

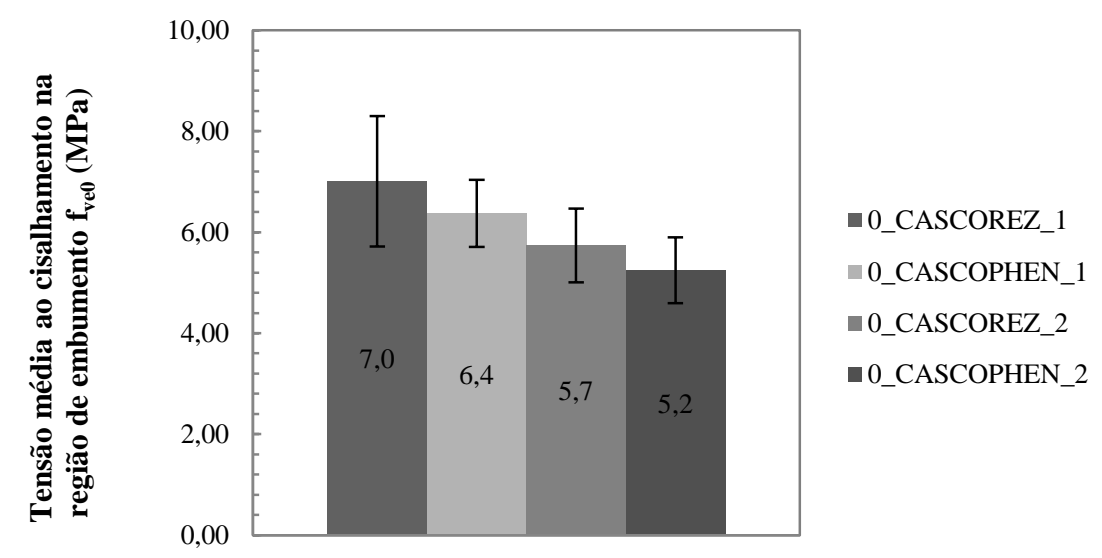

Figura 11 - Detalhes do ensaio das ligações a $90^{\circ}$

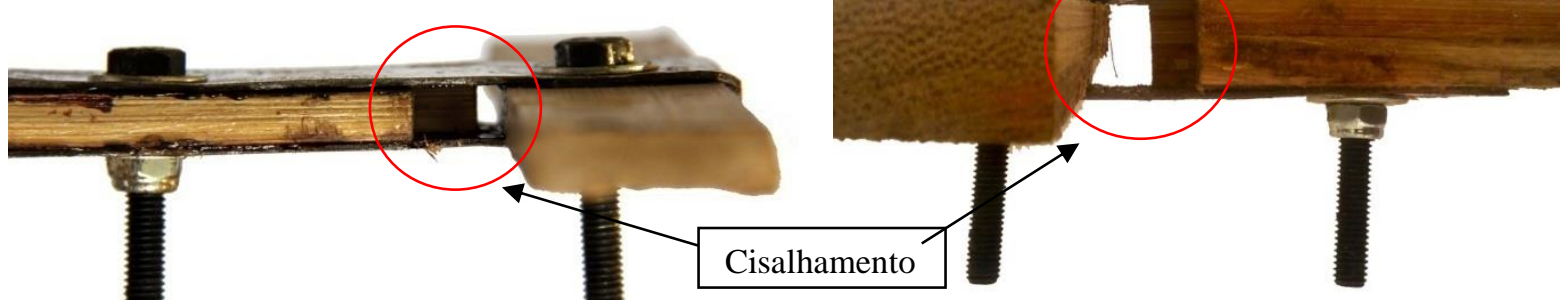

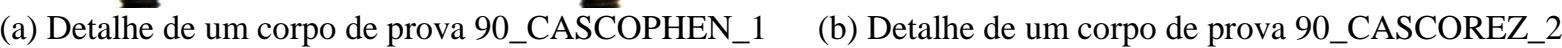
após o ensaio após o ensaio

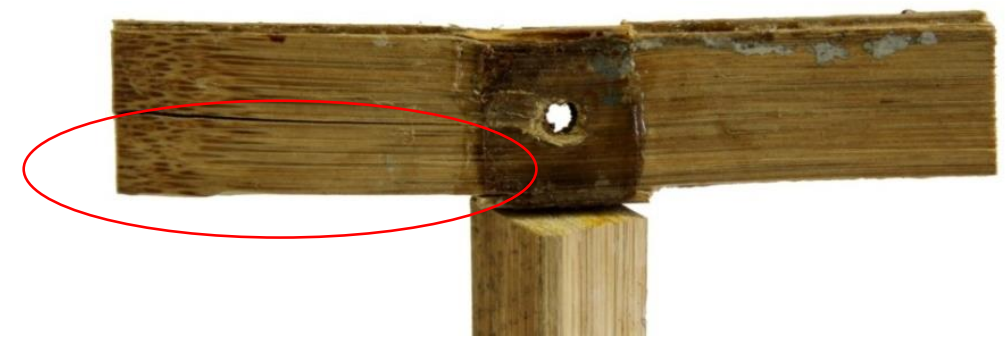

(c) Peça horizontal da ligação: ruptura por tração perpendicular às fibras (90_CASCOREZ_2) 
Figura 12 - Dados da tensão ao cisalhamento na região embutida para ligações a $90^{\circ}$

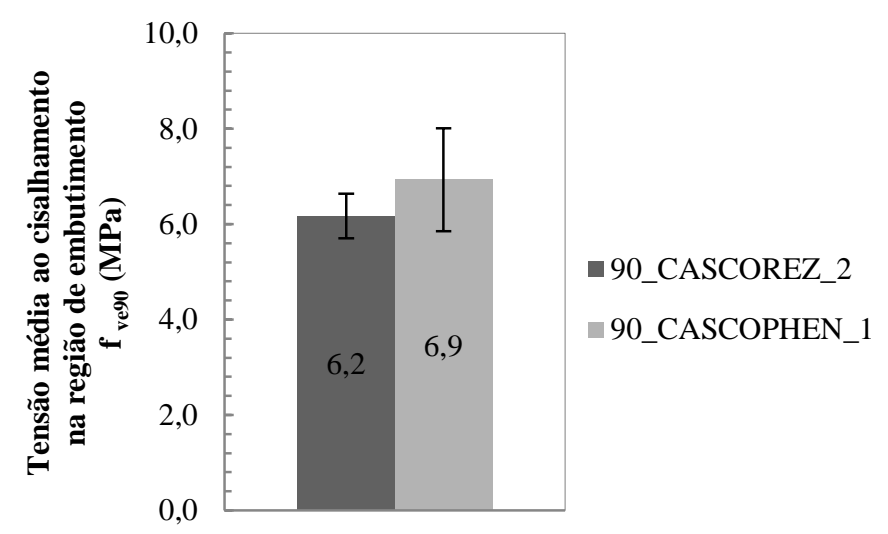

\section{Treliças planas do tipo Howe}

Para efeito de comparação realizou-se uma análise numérica das treliças na qual se admitiu comportamento elástico linear até um nível de carga correspondente a $70 \%$ da carga de ruptura. $\mathrm{Na}$ Figura 13 mostram-se os gráficos carga vs. deslocamento referentes às quatro treliças ensaiadas, conforme a seguinte denominação: EXP_CASCOREZ1, NUM_CASCOREZ1, EXP_CASCOREZ2, NUM_CASCOREZ2, EXP_CASCOPHEN1, NUM_CASCOPHEN1, EXP_CASCOPHEN2 e NUM_CASCOPHEN2 (conforme legenda da Figura 13a). O prefixo "EXP" designa os dados experimentais, e o "NUM" indica os resultados numéricos. Além disso, o número seguinte indica a célula de carga/LVDT referido; por exemplo, EXP_CASCOPHEN1_3: curva carga vs. deslocamento experimental referente à célula de carga/LVDT número 3 da treliça número 1 fabricada à base de adesivo Cascophen.

Analisando-se as curvas carga vs. deslocamento (Figura 13) observa-se claramente que as treliças à base de BLC fabricadas com adesivo Cascophen apresentaram capacidade de carga superior àquelas fabricadas utilizando-se adesivo Cascorez. As curvas da Figura 13 apresentam de forma geral o mesmo comportamento. Percebe-se que em todos gráficos a carga C2 (no meio do vão da treliça) apresenta valores inferiores em relação às demais (C1 e C3); além disso, os deslocamentos L2 (meio do vão) apresentam valores mais elevados do que os demais (L1 e L3). As cargas de ruptura C2 em relação às médias das cargas de ruptura $\mathrm{C} 1$ e $\mathrm{C} 3$ correspondem a $69,5 \%, 75,5 \%, 73,5 \%$ e $71,5 \%$ para as treliças CASCOREZ_1, CASCOREZ_2,
CASCOPHEN_1 e CASCOPHEN_2 respectivamente. No entanto, tal disparidade entre as cargas não prejudicou os ensaios, pois ainda assim se obteve simetria de carregamento e de geometria, já que as cargas extremas (C1 e C3) não se mostraram significativamente diferentes. $\mathrm{Na}$ Tabela 3 expõem-se as cargas de ruptura correspondentes às quatro treliças ensaiadas e o percentual de superioridade da capacidade de carga dessas quando comparadas à carga total $(2,1 \mathrm{kN})$ de projeto.

Os deslocamentos experimentais máximos verticais no meio do vão das treliças foram iguais a $7,41 \mathrm{~mm}, 8,26 \mathrm{~mm}, 7,58 \mathrm{~mm}$ e $14,45 \mathrm{~mm}$ para as treliças CASCOREZ_1, CASCOREZ_2, CASCOPHEN_1 e CASCOPHEN_2 respectivamente. A carga de serviço aplicada em cada um dos três nós superiores da treliça é igual a $0,42 \mathrm{kN}$; para esse carregamento obtiveram-se os seguintes deslocamentos experimentais máximos nas treliças: $2,15 \mathrm{~mm}, 2,15 \mathrm{~mm}, 1,39 \mathrm{~mm}$ e $2,82 \mathrm{~mm}$ para as treliças CASCOREZ_1, CASCOREZ_2, CASCOPHEN_1 e CASCOPHEN_2 respectivamente. Na Figura 14 mostra-se a configuração de deslocamentos da treliça para o carregamento de serviço, a qual foi obtida no Ftool segundo um fator de escala igual a 70 .

À exceção da treliça CASCOPHEN_2, os dados experimentais de deslocamento se aproximam dos valores numéricos, principalmente para uma carga próxima à de projeto. Acredita-se que os deslocamentos excessivos da treliça CASCOPHEN_2 sejam provenientes de escorregamento das barras devido a alguma folga existente na região de ligação (nó). 
Figura 13 - Gráfico carga vs. deslocamento das treliças planas de BLC do tipo Howe

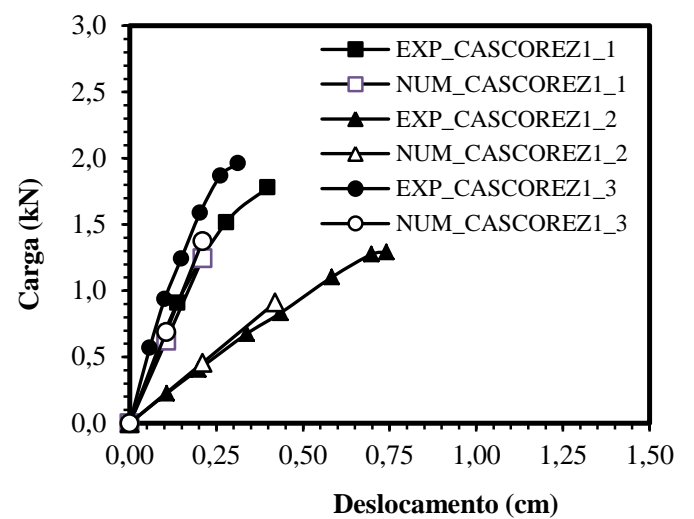

(a) Treliça CASCOREZ_1

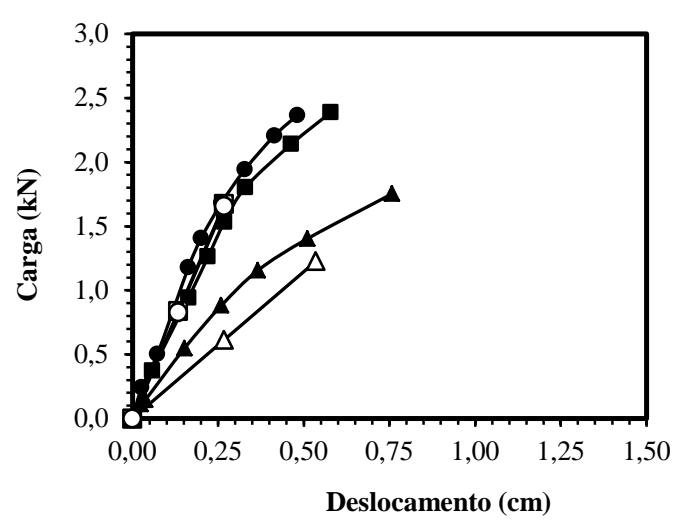

(c) Treliça CASCOPHEN_1

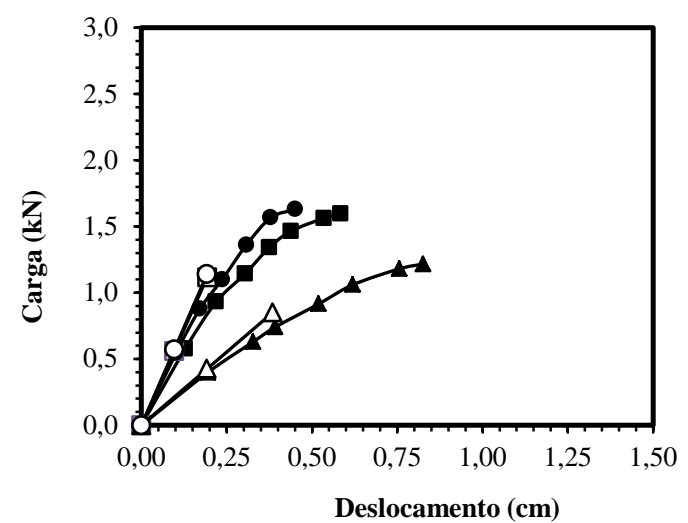

(b) Treliça CASCOREZ_2

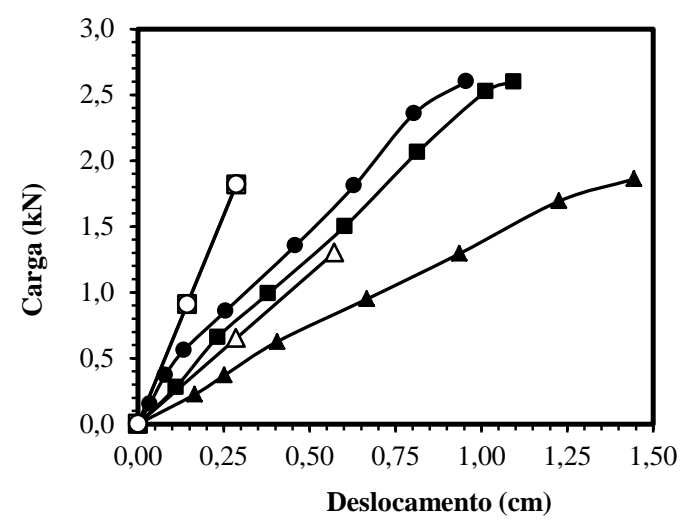

(d) Treliça CASCOPHEN_2

Tabela 3 - Cargas de ruptura das treliças ensaiadas

\begin{tabular}{ccccc}
\hline Treliça & $\mathbf{C 1}(\mathbf{k N})$ & $\mathbf{C 2}(\mathbf{k N})$ & $\mathbf{C 3}(\mathbf{k N})$ & $\begin{array}{c}\text { Comparação relativa à } \\
\text { carga de projeto }\end{array}$ \\
\hline PROJETO & 0,70 & 0,70 & 0,70 & - \\
CASCOREZ_1 & 1,78 & 1,30 & 1,96 & $140 \%$ \\
CASCOREZ_2 & 1,60 & 1,22 & 1,63 & $110 \%$ \\
CASCOPHEN_1 & 2,39 & 1,75 & 2,37 & $210 \%$ \\
CASCOPHEN_2 & 2,60 & 1,86 & 2,60 & $240 \%$ \\
\hline
\end{tabular}

Figura 14 - Deslocamentos da treliça para condições de serviço

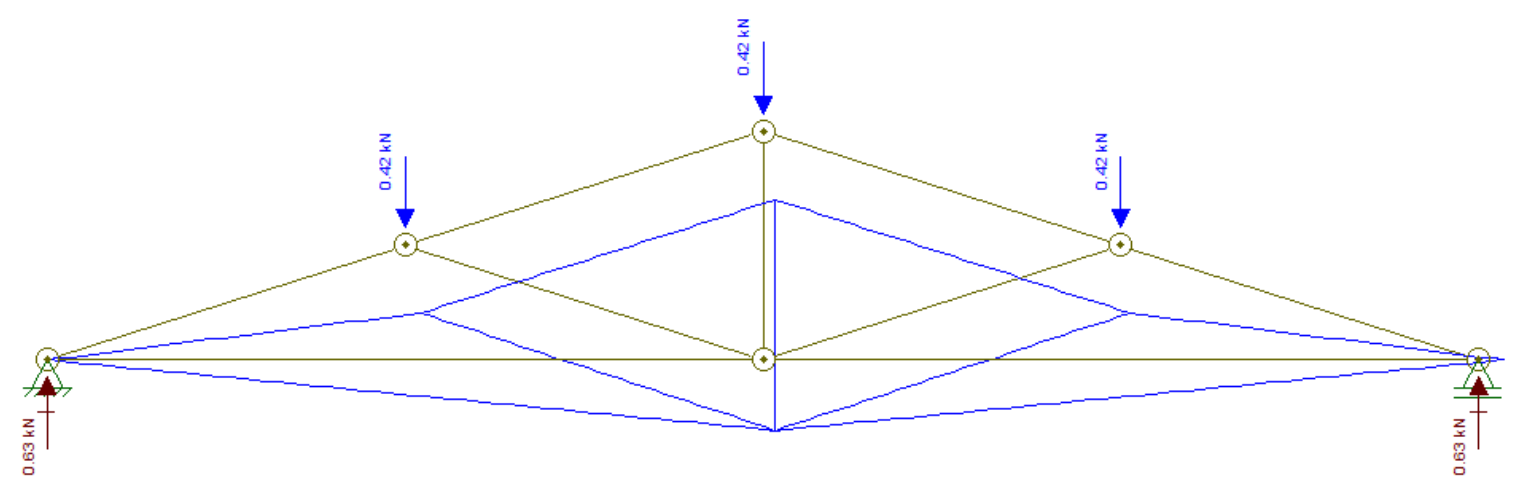

96 Lima, D. M. de; Amorim, M. M.; Lima Júnior, H. C.; Barbosa, N. P.; Wilrich, F. L. 
A partir das leituras de deformação dos extensômetros que foram instalados nas barras 1 , 2, 3 e 4 da treliça, obtiveram-se os resultados de tensão nas respectivas barras. Esses valores de tensão foram calculados pela lei de Hooke utilizando-se o módulo de elasticidade à compressão paralela às fibras do bambu (LIMA, 2013). Para efeito de comparação, calcularam-se as tensões teóricas atuantes nas barras das treliças. Esses valores de tensão foram calculados a partir das forças nas barras e das áreas das seções transversais.

Com base em Calil Junior, Marin e Palma (2004) e em Fernández (2010) construíram-se os gráficos das tensões atuantes nas barras vs. carregamento total. Nesses gráficos os prefixos NUM e TEO significam dados numérico e teórico respectivamente. O carregamento total aplicado resulta das somas dos valores das três cargas aplicadas à treliça durante o ensaio.
Para a treliça CASCOREZ_1 observa-se que os dados de tensões nas barras versus carregamentos totais aplicados nas análises teórica e experimental das barras 2, 3 e 4 mostram-se similares (Figura 15). As tensões normais máximas de tração teórica e experimental obtidas foram iguais a 19,47 MPa e 19,02 MPa respectivamente, ambas para a barra 3; tais valores, mesmo sob condições da capacidade resistente máxima, apresentaram-se inferiores à resistência de cálculo à tração paralela às fibras na região nodal do bambu igual a 26,19 MPa (LIMA, 2013). As tensões normais máximas de compressão teórica e experimental obtidas foram iguais a $15,23 \mathrm{MPa}$ (barra 2) e $14,70 \mathrm{MPa}$ (barra 4) respectivamente; esses valores, mesmo sob condições da capacidade resistente máxima, apresentaram-se inferiores à resistência de cálculo à compressão paralela às fibras do BLC (fabricado com adesivo Cascorez) igual a 43,45 MPa (LIMA, 2013). A treliça CASCOREZ_1 rompeu por flambagem na barra 2.

Figura 15 - Gráficos tensão vs. carregamento total da treliça CASCOREZ_1

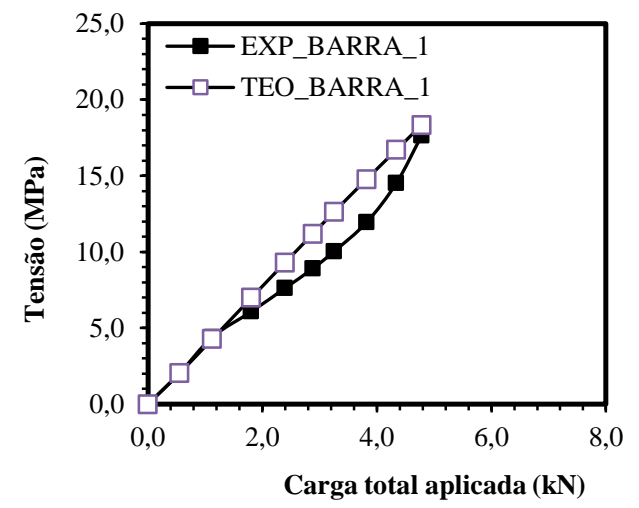

(a) Barra 1 - tracionada

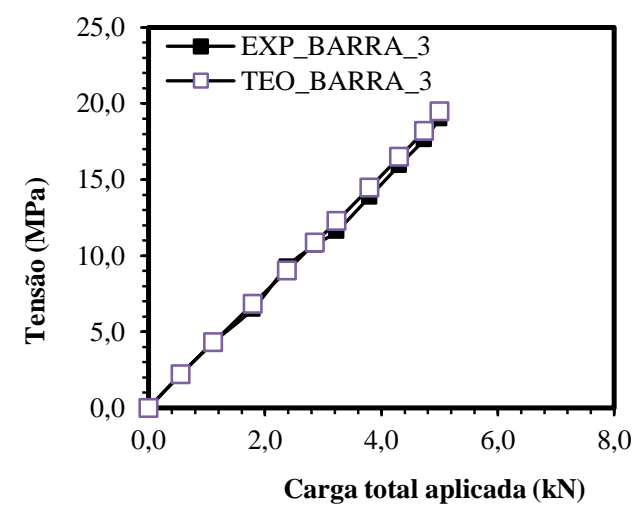

(c) Barra 3 - tracionada

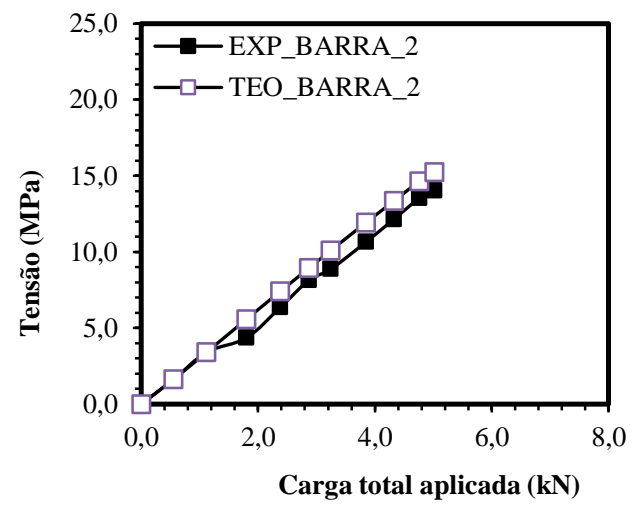

(b) Barra 2 - comprimida

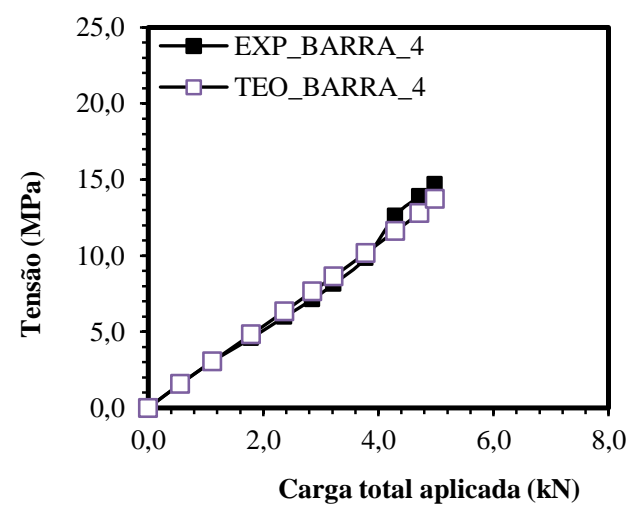

(d) Barra 4 - comprimida 
Para a treliça CASCOREZ_2 observa-se que as relações entre os carregamentos totais aplicados e as tensões normais, quando comparadas as análises teórica e experimental das barras 1, 2 e 3, apresentam comportamento similares (Figura 16). Para a barra 4 houve relevantes discrepâncias entre as tensões teóricas e experimentais, provavelmente pelo acréscimo de deformação devido à flexão proveniente da flambagem dessa barra. As tensões normais máximas de tração teórica e experimental obtidas foram iguais a $16,85 \mathrm{MPa}$ e $15,14 \mathrm{MPa}$ respectivamente, ambas para a barra 3; tais valores, mesmo sob condições da capacidade resistente máxima, apresentaram-se inferiores à resistência de cálculo à tração paralela às fibras na região nodal do bambu igual a 26,19 MPa (LIMA, 2013). As tensões normais máximas de compressão teórica e experimental obtidas foram iguais a $12,74 \mathrm{MPa}$ (barra 2) e 20,49 $\mathrm{MPa}$ (barra 4) respectivamente; esses valores, mesmo sob condições da capacidade resistente máxima, apresentaram-se inferiores à resistência de cálculo à compressão paralela às fibras do BLC (fabricado com adesivo Cascorez) igual a 43,45 MPa (LIMA, 2013). Para a treliça CASCOREZ_2 observou-se ruptura por flambagem na barra 4 .
Para a treliça CASCOPHEN_1, observa-se que os dados experimentais de tensão das barras 1, 3 e 4 apresentaram valores inferiores aos das tensões teóricas, enquanto que para a barra 2 , que não sofreu flambagem, os valores de tensões experimentais mostraram-se superiores aos teóricos (Figura 17). As tensões normais máximas de tração teórica e experimental obtidas foram iguais a 23,89 $\mathrm{MPa}$ (barra 1) e 18,71 MPa (barra 3 ), respectivamente; tais valores, mesmo sob condições da capacidade resistente máxima, apresentaram-se inferiores à resistência de cálculo à tração paralela às fibras na região nodal do bambu igual a 26,19 MPa (LIMA, 2013). As tensões normais máximas de compressão teórica e experimental obtidas foram iguais a $19,30 \mathrm{MPa}$ (barra 4) e 22,46 MPa (barra 2), respectivamente; estes valores, mesmo sob condições da capacidade resistente máxima, apresentaram-se inferiores à resistência de cálculo à compressão paralela às fibras do BLC (fabricado com adesivo Cascophen) igual a 41,02 MPa (LIMA, 2013). A treliça CASCOPHEN_1 rompeu por flambagem na barra 4.

Figura 16 - Gráficos tensão vs. carregamento total da treliça CASCOREZ_2

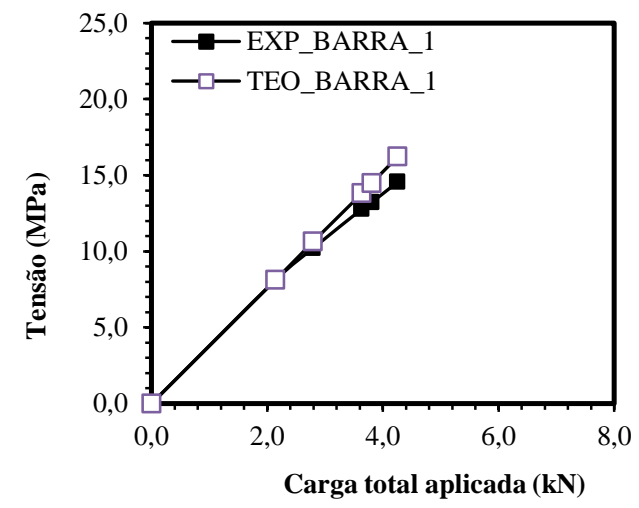

(a) Barra 1 - tracionada

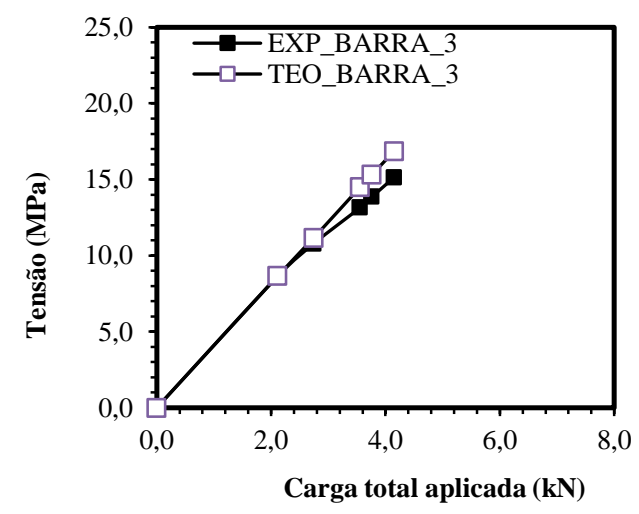

(c) Barra 3 - tracionada

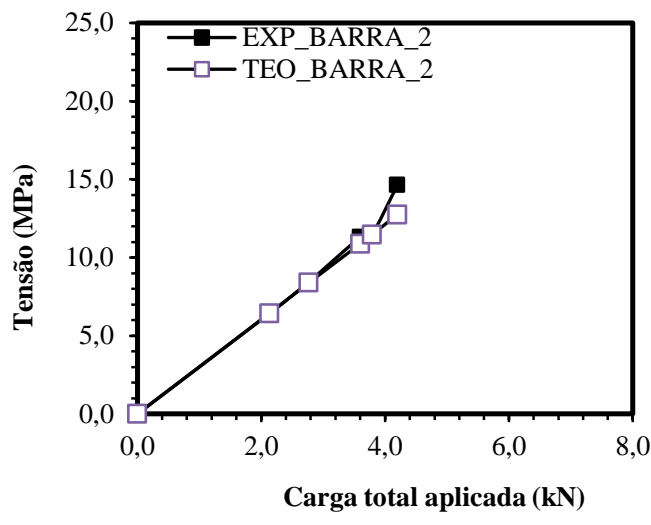

(b) Barra 2 - comprimida

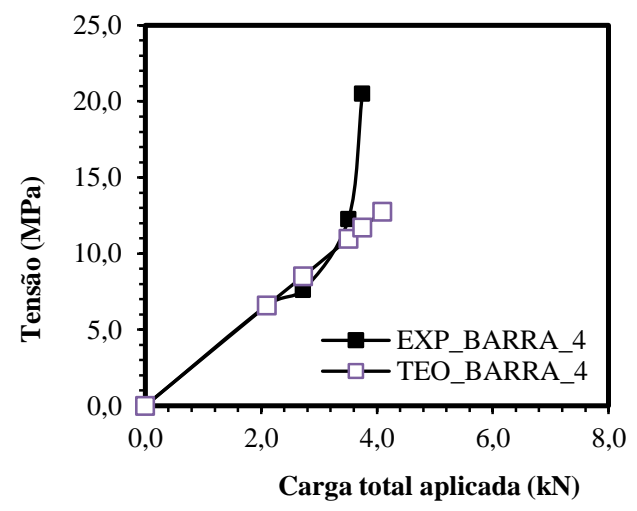

(d) Barra 4 - comprimida

98 Lima, D. M. de; Amorim, M. M.; Lima Júnior, H. C.; Barbosa, N. P.; Wilrich, F. L. 
Figura 17 - Gráficos tensão vs. carregamento total da treliça CASCOPHEN_1

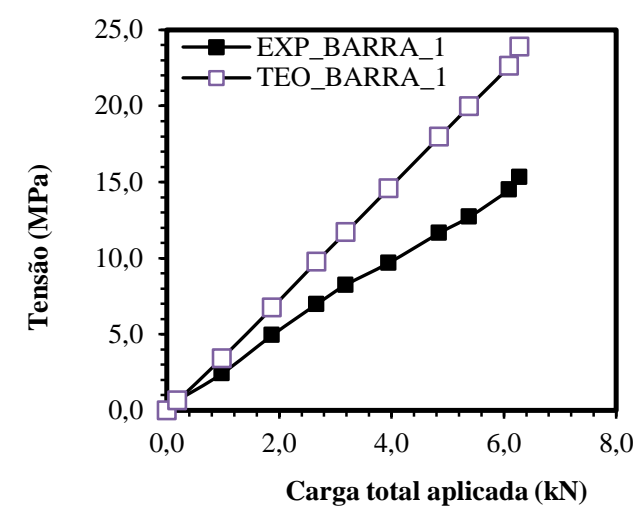

(a) Barra 1 - tracionada

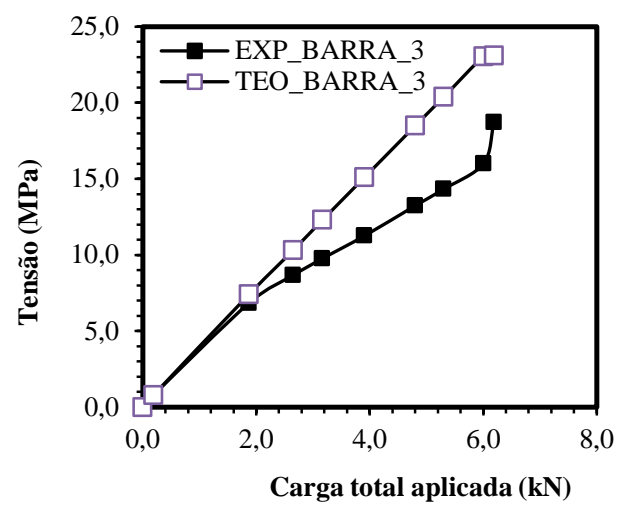

(c) Barra 3 - tracionada

As tensões normais máximas de tração teórica e experimental obtidas para a treliça CASCOPHEN_2 (Figura 18) foram iguais a 24,71 MPa (barra 1) e 19,18 MPa (barra 3) respectivamente; tais valores, mesmo sob condições da capacidade resistente máxima, apresentaram-se inferiores à resistência de cálculo à tração paralela às fibras na região nodal do bambu igual a 26,19 MPa (LIMA, 2013). As tensões normais máximas de compressão teórica e experimental obtidas foram iguais a $18,68 \mathrm{MPa}$ e 22,30 MPa respectivamente, ambas para a barra 2; esses valores, mesmo sob condições da capacidade resistente máxima, apresentaram-se inferiores à resistência de cálculo à compressão paralela às fibras do BLC (fabricado com adesivo Cascophen) igual a 41,02 MPa (LIMA, 2013). Os dados experimentais de tensão das barras 1 e 3 (tracionadas) apresentaram valores inferiores aos das tensões teóricas nessas barras. Para a barra 4, onde se iniciou a ruptura por flambagem, têm-se valores de tensão experimental inferiores aos valores de tensão numérica. Em seguida, após a flambagem da barra 4, observou-se a flambagem da barra 2. Dessa forma, para a treliça CASCOPHEN_2 houve ruptura por flambagem nas barras 2 e 4 .

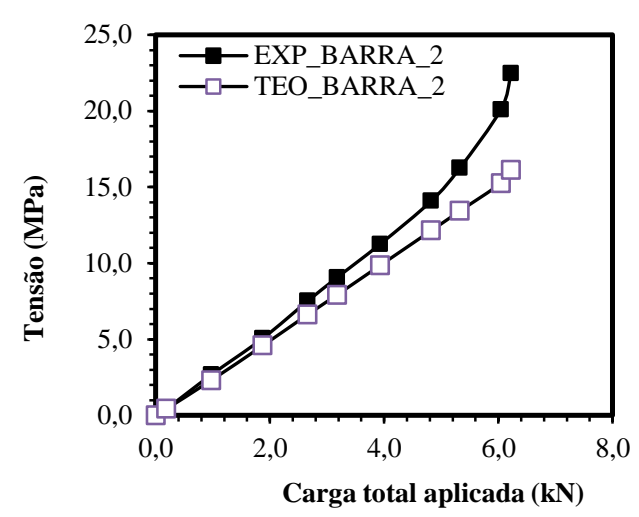

(b) Barra 2 - comprimida

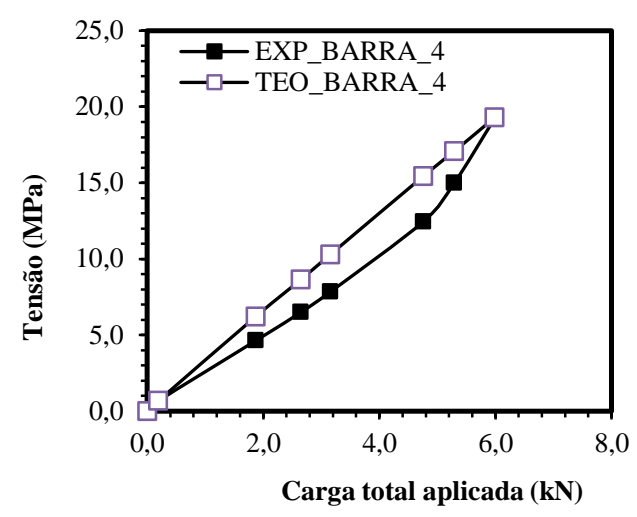

(d) Barra 4 - comprimida

Apesar de as treliças fabricadas com adesivo Cascophen terem apresentado maior capacidade de carga do que as produzidas com adesivo Cascorez, o tipo de adesivo não é um fator determinante na magnitude da capacidade de carga nem no comportamento estrutural de elementos axialmente carregados (elementos de treliça), uma vez que o modo de ruptura de todas as treliças ensaiadas foi similar (flambagem sob compressão). Na verdade, esse foi o critério determinante na ruptura de todas as treliças, uma vez que foi necessária a construção de treliças econômicas, com seções transversais reduzidas, para economizar o material de estudo (bambu da espécie Dendrocalamus giganteus). Os índices de esbeltezas máximos das barras comprimidas das treliças foram iguais a 107 para as barras 2, 4, 8 e 9, e 136 para as barras 5 e 6 . Portanto, todas as barras comprimidas da treliça ensaiada são classificadas como esbeltas (índice de esbeltez maior do que 80); adicionalmente, as barras 5 e 6 têm índice de esbeltez muito próximo ao limite de 140 estabelecido pela norma supracitada. Por fim, mostra-se na Figura 19 o modo de ruptura (flambagem) ocorrido nas quatro treliças ensaiadas. 
Figura 18 - Gráficos tensão vs. carregamento total da treliça CASCOPHEN_2

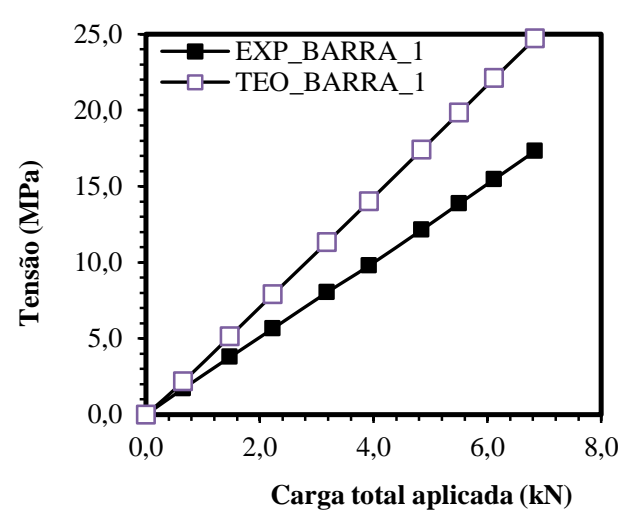

(a) Barra 1 - tracionada

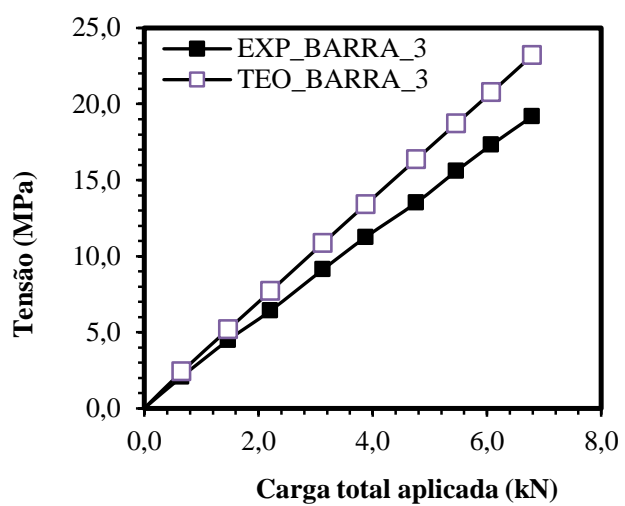

(c) Barra 3 - tracionada

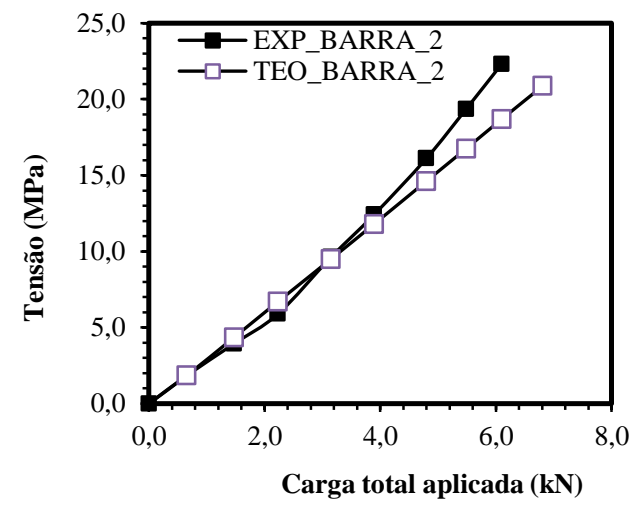

(b) Barra 2 - comprimida.

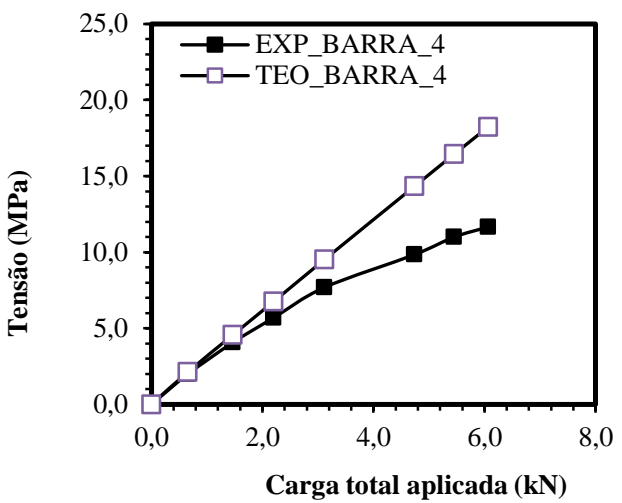

(d) Barra 4 - comprimida

Figura 19 - Vistas da ruptura por flambagem das treliças ensaiadas

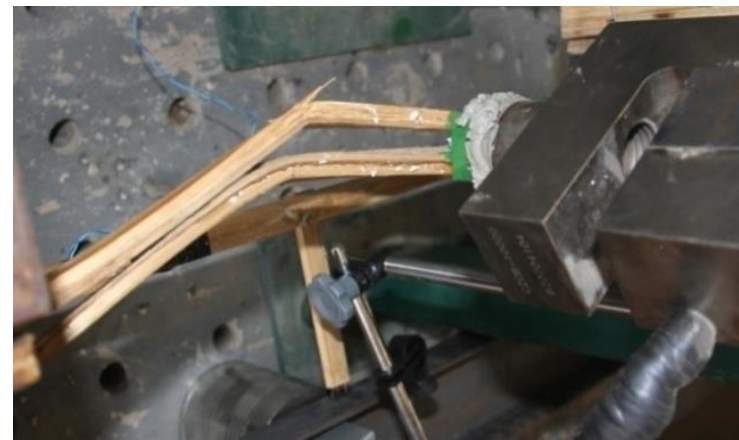

(a) Cascorez 1

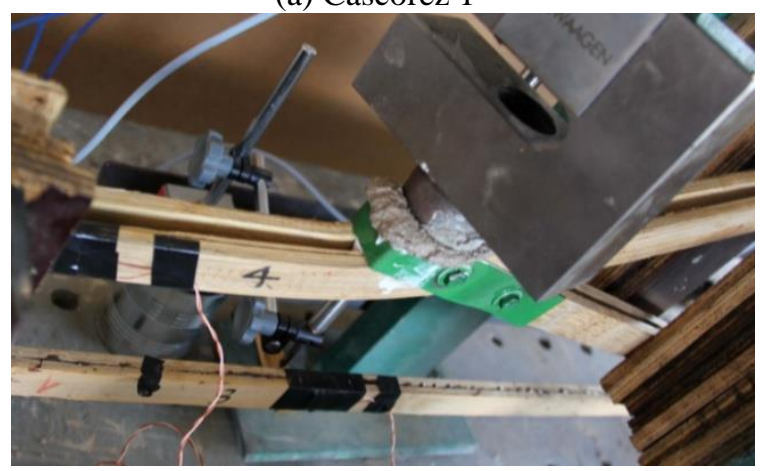

(c) Cascophen 1

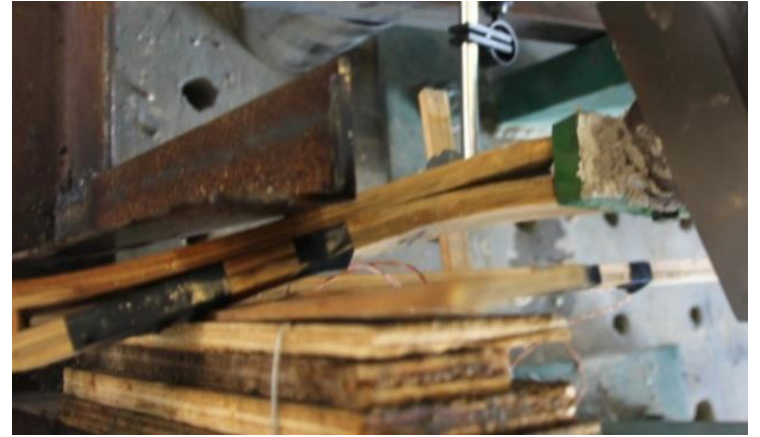

(b) Cascorez 2

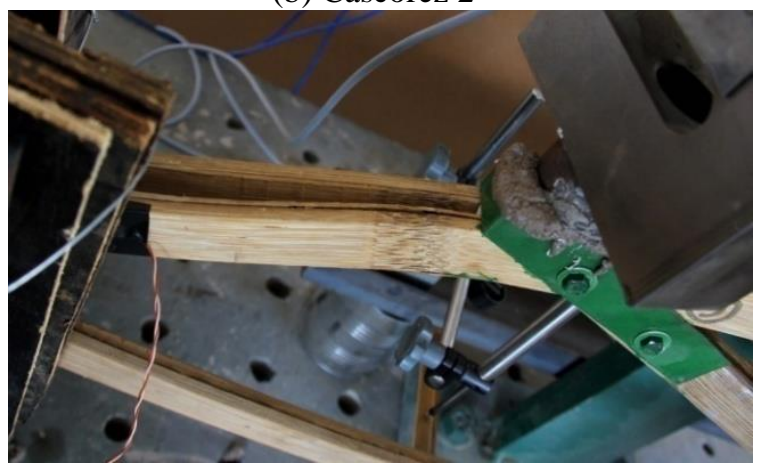

(d) Cascophen 2

100 Lima, D. M. de; Amorim, M. M.; Lima Júnior, H. C.; Barbosa, N. P.; Wilrich, F. L. 


\section{Considerações finais}

Com relação aos ensaios das ligações metálicas das treliças a $0^{\circ}$, concluiu-se que a ruptura ocorreu por cisalhamento na região de embutimento do parafuso para todas as combinações de adesivos e quantidades de ripas utilizadas. Adicionalmente, avaliou-se que o tipo de adesivo utilizado não influenciou na tensão ao cisalhamento da região embutida. Para as ligações metálicas das treliças a $90^{\circ}$, verificou-se que a ruptura ocorreu por cisalhamento na região de embutimento do parafuso sobre o bambu ou por tração perpendicular às fibras.

Para as treliças o adesivo Cascophen apresentou-se mais eficiente do que o adesivo Cascorez; em contrapartida, deve ser levado em consideração o custo extremamente inferior do adesivo Cascorez em relação ao Cascophen (de 15 a 20 vezes), uma vez que aquele atendeu, com folga, às especificações de segurança dos códigos normativos utilizados. Portanto, para o uso sob condições de impermeabilização (aplicação em interiores ou sob tratamento) e em elementos estruturais submetidos a esforços axiais, o adesivo Cascorez resulta em uma alternativa de menor custo para a produção de laminados colados de bambu.

O comportamento carga vs. deslocamento experimental apresentou-se semelhante ao comportamento numérico, principalmente para um nível de carregamento próximo ao de projeto. A exceção pode ser atribuída à treliça CASCOPHEN_2, que apresentou valores de deslocamentos experimentais superiores aos dados numéricos, fato que pode ter ocorrido devido à não linearidade de contato nas vinculações dessa treliça.

Por fim, a análise teórico-experimental dos gráficos de tensão nas barras vs. carregamento mostrou que o comportamento das treliças ocorreu de modo satisfatório até cerca de $70 \%$ da carga máxima; a partir desse valor observaram-se discrepâncias entre dados experimentais e teóricos, que foram provenientes do modo de colapso das treliças (flambagem sob compressão).

\section{Referências}

ALVIM, R. de C. Projeto de Estruturas de Madeira: peças compostas comprimidas. São Paulo: Blucher Acadêmico, 2009.

ASSOCIAÇÃO BRASILEIRA DE NORMAS TÉCNICAS. NBR 6123: forças devidas ao vento em edificações. Rio de Janeiro, 1988.
CALIL JUNIOR, C.; MARIN, C. P.; PALMA, G.

Ponte Treliçada Modular Pré-Fabricada de Madeira. In: ENCONTRO BRASILEIRO EM MADEIRAS E EM ESTRUTURAS DE MADEIRA, 9., Cuiabá, 2004. Anais... Cuiabá, 2004.

\section{FERNÁNDEZ, B. O. Sistemas de Treliças} Modulares Para Pontes de Madeira: uma boa alternativa para o estado do Pará. São Carlos, 2010. 132 f. Dissertação (Mestrado em Engenharia de Estruturas) - Escola de Engenharia,

Universidade de São Paulo, São Carlos, 2010.

FOREST PRODUCTS LABORATORY. Wood

Handbook: wood as an engineering material. Gen. Tech. Rep. FPL-GTR-113. Madison, WI: U.S Department of Agriculture, Forest Service, Forest Products Laboratory, 1999.

GHAVAMI, K.; RODRIGUES, C. de S.; PACIORNIK, S. Bamboo: functionally graded composite material. Asian Journal of Civil Engineering, Irã, v. 4, n. 1, p. 1-10, 2003.

LIMA, D. M. de. Bambu Laminado Colado (Dendrocalamus giganteus) Aplicado à Treliça Plana Tipo Howe e à Viga Retangular. Recife, 2013. 234 f. Dissertação (Mestrado em Engenharia Civil) - Escola de Engenharia, Universidade Federal de Pernambuco, Recife, 2013.

LIMA JUNIOR., H. C.; DIAS, A. A. Vigas Mistas de Madeira de Reflorestamento e Bambu Laminado Colado: análise teórica e experimental. Revista Brasileira de Engenharia Agrícola e Ambiental, Campina Grande, PB, v. 5, n. 3, p. 519-524, 2001

MESQUITA, L. P. et al. Determinação da Tensão de Aderência de Cálculo Bambu-Concreto.

Revista Brasileira de Engenharia Agrícola e Ambiental, Campina Grande, v. 10, n. 2, p. 505516, 2006.

MOLiTERnO, A. Caderno de Projetos de Telhados em Estruturas de Madeira. 4. ed. São Paulo: Blucher, 2010

PEREIRA, M. A. dos R.; BERALDO, A. L.

Bambu de Corpo e Alma. Bauru: Canal6, 2008.

ROSA, S. P. A. P. Análise Teórica e

Experimental de Colunas de Concreto Armado Com Bambu. Rio de Janeiro, 2002. 135 f.

Dissertação (Mestrado em Ciências de Engenharia Civil) - Pontifícia Universidade Católica do Rio de Janeiro, Rio de Janeiro, 2002.

\section{Agradecimentos}

Ao Laboratório de Modelos Reduzidos da Universidade Estadual do Oeste do Paraná 
(Unioeste), pela doação do bambu utilizado neste trabalho.

Ao Laboratório de Sistemas Construtivos (LSC) do Centro Acadêmico do Agreste (CAA) da
Universidade Federal de Pernambuco (UFPE), onde foram realizados os ensaios desta pesquisa.

À Fundação de Amparo à Ciência e Tecnologia do Estado de Pernambuco (FACEPE), pela concessão da bolsa de mestrado ao primeiro autor.

\section{Douglas Mateus de Lima}

Núcle de Tecnologia, Centro Acadêmico do Agreste | Universidade Federal de Pernambuco | Rodovia BR 104, km 59, Sítio Juriti, Campus do Agreste, Nova Caruaru | Caruaru - PE - Brasil | CEP 55002-970 | Tel.: (81) 2126-7771 | E-mail: douglasortoedro@gmail.com

\section{Mariana Mendes Amorin}

Núcle de Tecnologia, Centro Acadêmico do Agreste | Universidade Federal de Pernambuco | E-mail: amorim.mariana@gmail.com

Humberto Correia Lima Júnior

Núcle de Tecnologia, Centro Acadêmico do Agreste | Universidade Federal de Pernambuco | E-mail: humbertolima@ufpe.br

\section{Normando Perazzo Barbosa}

Centro de Tecnologia | Universidade Federal da Paraíba | Campus I, Cidade Universitária LABEME, Castelo Branco | João Pessoa - PB Brasil | CEP 58051-900 | Tel.: (83) 3216-7910 | E-mail: nperazzob@yahoo.com.br

\section{Fábio Luiz Wilrich}

ITAIPU Binacional | Av. Tancredo Neves 6731, CP 1555 | Foz do Iguaçu - PR - Brasil | CEP 85856-000 | E-mail: miriamfabio@gmail.com

\section{Revista Ambiente Construído}

Associação Nacional de Tecnologia do Ambiente Construído

Av. Osvaldo Aranha, $99-3^{\circ}$ andar, Centro

Porto Alegre - RS - Brasil

CEP $90035-190$

Telefone: +55 (51) 3308-4084

Fax: +55 (51) 3308-4054

www.seer.ufrgs.br/ambienteconstruido

E-mail: ambienteconstruido@ufrgs.br 